Linköping University Medical Dissertations

No. 1453

\title{
UPPER AIRWAY MUCOSAL INFLAMMATION: PROTEOMIC STUDIES AFTER EXPOSURE TO IRRITANTS AND MICROBIAL AGENTS
}

\author{
Louise Fornander
}

\section{Linköping University FACULTY OF HEALTH SCIENCES}

Occupational and Environmental Medicine Department of Clinical and Experimental Medicine Faculty of Health Sciences, Linköping University SE-581 85 Linköping, Sweden 
(C) Louise Fornander, 2015

Paper I is reprinted with kind permission from John Wiley and Sons (published in Proteomics - Clinical Applications). Paper II is reprinted with kind permission from Springer (published in International Archives of Occupational and Environmental Health). Ownership of copyright for Paper III, originally published by PLoS One 2013, remains with the authors.

ISBN: 978-91-7519-129-4

ISSN: 0345-0082

Cover was created by the author and produced by Martin Pettersson, LiU-Tryck.

Printed by LiU-Tryck, Linköping 2015 
'’Det är lugnt!'

Användbart uttryck frekvent nyttjat av författaren vid alla tänkbara tillfällen. 
SUPERVISOR

Mats Lindahl, Linköping University, Sweden

\section{CO-SUPERVISORS}

Bijar Ghafouri, Linköping University, Sweden

Pål Graff, Örebro University Hospital, Sweden

\section{FUNDING}

This work was supported by the Research Council of South East Sweden and the Cancer and Allergy Foundation. 


\section{ABSTRACT}

People are, in their daily lives, exposed to a number of airborne foreign compounds that do not normally affect the body. However, depending on the nature of these compounds, dose and duration of exposure, various airway symptoms may arise. Early symptoms are often manifested as upper airway mucosal inflammation which generates changes in protein composition in the airway lining fluid.

This thesis aims at identifying, understanding mechanisms and characterizing protein alterations in the upper airway mucosa that can be used as potential new biomarkers for inflammation in the mucosa. The protein composition in the mucosa was studied by sampling of nasal lavage fluid that was further analyzed with a proteomic approach using two-dimensional gel electrophoresis and mass spectrometry. Additionally, by studying factors on site through environmental examination, health questionnaires and biological analyses, we have tried to understand the background to these protein alterations and their impact on health.

Respiratory symptoms from the upper airways are common among people who are exposed to irritative and microbial agents. This thesis have focused on personnel in swimming pool facilities exposed to trichloramine, metal industry workers exposed to metalworking fluids, employees working in damp and moldy buildings and infants diagnosed with respiratory syncytial virus infection. The common denominator in these four studies is that the subjects experience upper airway mucosal inflammation, which is manifested as cough, rhinitis, phlegm etc. In the three occupational studies, the symptoms were work related. Notably, a high prevalence of perceived mucosal symptoms was shown despite the relatively low levels of airborne irritants revealed by the environmental examination. Protein profiling verified an ongoing inflammatory response by identification of several proteins that displayed altered levels. Interestingly, innate immune proteins dominated and four protein alterations occurred in most of the studies; SPLUNC1, protein S100A8 and S100A9 and alpha-1antitrypsin. Similarly, these proteins were also found in nasal fluid from children with virus infection and in addition a truncated form of SPLUNC1 and two other S100 proteins (S100A7-like 2 and S100A16), not previously found in nasal secretion, were identified. 
Altogether, the results indicate the potential use of a proteomic approach for identifying new biomarkers for the upper respiratory tract at an early stage in the disease process after exposure to irritant and microbial agents. The results indicate an effect on the innate immunity system and the proteins; SPLUNC1, protein S100A8 and S100A9 and alpha-1-antitrypsin are especially promising new biomarkers. Moreover, further studies of these proteins may help us to understand the molecular mechanisms involved in irritant-induced airway inflammation. 


\section{POPULÄRVETENSKAPLIG SAMMANFATTNING}

\section{FÖRÄNDRAD PROTEINSAMMANSÄTTNING I DE ÖVRE LUFTVÄGARNA EFTER EXPONERING FÖR SLEMHINNEIRRITERANDE ÄMNEN}

Varje dag utsätts vi för partiklar och ämnen i vår omgivningsluft, som vanligtvis inte påverkar oss. Beroende på ämnenas irriterande egenskaper, mängderna som inandas och hur ofta eller hur lång tid som vi exponeras så kan de dock ge upphov till luftvägssjukdom. Något som kan drabba personer som i sitt arbete är exponerade för irriterande kemikalier. Tidiga effekter märks ofta som besvär i de övre luftvägarna beroende på en inflammation i slemhinnan. Denna slemhinna utgör normalt ett skydd mot att inandade partiklar förs ner i lungorna och innehåller bland annat celler och ett stort antal proteiner där flera är viktiga $i$ vårt medfödda immunförsvar mot bakterier och virus. Förändringar i slemhinnans sammansättning är möjliga att undersöka med hjälp av nässköljning med koksaltlösning. Genom att analysera proteinerna i nässköljvätskan med ny teknik, proteomik, kan man urskilja vilka typer av proteiner som reagerat på en viss exponering och få ökad förståelse för de bakomliggande sjukdomsmekanismerna. Syftet med denna avhandling har därför varit att hitta specifika proteiner som kan fungera som biomarkörer för inflammation i slemhinnan efter vistelse $\mathrm{i}$ arbetsmiljöer där man kan exponeras för irriterande ämnen. Utöver nässköljvätska har vi använt oss av luftanalyser på plats, hälsoenkäter samt andra biologiska analyser för att djupare förstå bakgrunden till arbetsmiljöns hälsopåverkan.

Vissa arbetsmiljöer är mer kända än andra för att ge upphov till luftvägsproblem. I den här avhandlingen har vi inriktat oss på personal som arbetar i simhallsmiljö och är exponerade för trikloraminer, industriarbetare exponerade för skärvätska och personer som arbetar i fuktskadade byggnader. Vi har även studerat barn med RS-virus (respiratory syncytial virus) infektion. Gemensamt för de fyra grupperna är risken för övre luftvägsproblem, som ger sig till känna till exempel genom hosta, slem, och rinnande näsa. I arbetsmiljöstudierna var symptomen arbetsplatsrelaterade, vilket betyder att besvären försvann vid ledighet. Våra resultat visade att en stor andel av personalen hade luftvägsproblem trots relativt låga nivåer av uppmätta luftvägsirritanter. Analyserna av nässköljvätska visade på effekter i luftvägarna genom flertalet förändrade proteinnivåer. Fyra proteiner som ingår $i$ vårt medfödda 
immunförsvar återkom i flera av studierna; SPLUNC1, protein S100A8 och S100A9, och alpha-1-antitrypsin, och utgör potentiellt viktiga biomarkörer.

Avhandlingen visar att analys av nässköljvätska kan användas för att hitta och mäta biomarkörer för inflammation i de övre luftvägarna och tyder på att exponering för irriterande ämnen leder till effekter på vårt medfödda immunförsvar. Resultaten kan få betydelse för att $\mathrm{i}$ ett tidigt skede kunna påvisa luftvägseffekter hos personer som är exponerade för irriterande ämnen vilket skulle underlätta möjligheterna till att snabbare kunna sätta in behandling och genomföra arbetsmiljöförbättrande åtgärder för att undvika att fler personer drabbas. 
This thesis is based on the following papers, which are referred to in the text by their Roman numerals.

\section{Paper I}

Fornander L., Ghafouri B., Kihlström E., Åkerlind B., Schön T., Tagesson C., Lindahl M. Innate immunity proteins and a new truncated form of SPLUNC1 in nasopharyngeal aspirates from infants with respiratory syncytial virus infection. Proteomics Clin. Appl. 2011;5(9-10):513-22.

\section{Paper II}

Fornander L., Ghafouri B., Lindahl M., Graff P. Airway irritation among indoor swimming pool personnel: trichloramine exposure, exhaled NO and protein profiling of nasal lavage fluids. Int Arch Occup Environ Health. 2013;86(5):571-80.

Paper III

Fornander L., Graff P., Wåhlén K., Ydreborg K., Flodin U., Leanderson P., Lindahl M., Ghafouri B. Airway symptoms and biological markers in nasal lavage fluid in subjects exposed to metalworking fluids. PLoS One. 2013;31;8(12).

\section{Paper IV}

Wåhlén K., Fornander L., Olausson P., Flodin U., Graff P., Lindahl M., Ghafouri B. Potential biomarkers in nasal lavage fluid from individuals with work-related upper airway symptoms associated to moldy and damp buildings. Submitted. 



\section{TABLE OF CONTENTS}

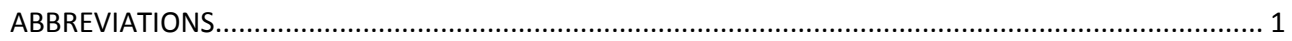

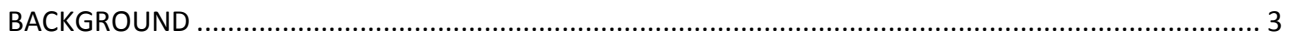

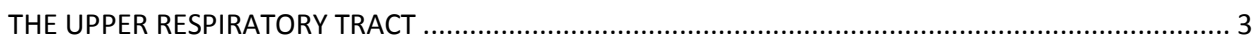

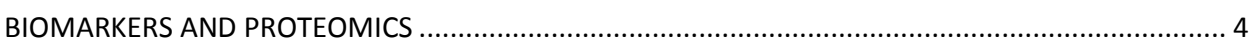

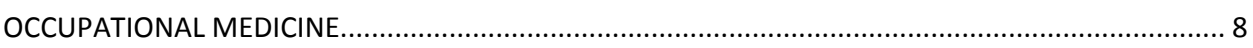

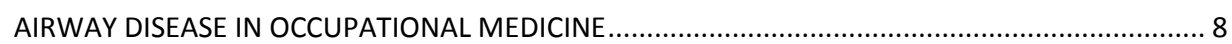

OCCUPATIONAL EXPOSURES AFFECTING THE RESPIRATORY SYSTEM ................................... 8

OCCUPATIONAL RHINITIS AND OCCUPATIONAL ASTHMA ….................................................. 9

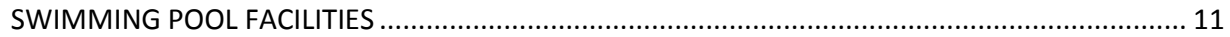

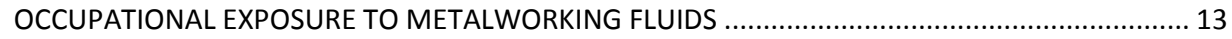

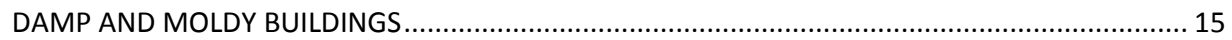

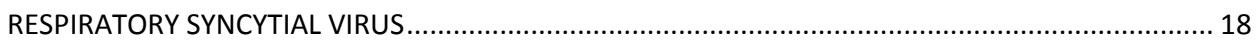

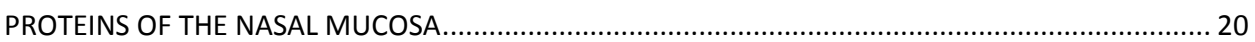

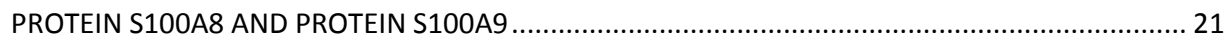

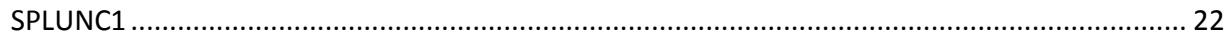

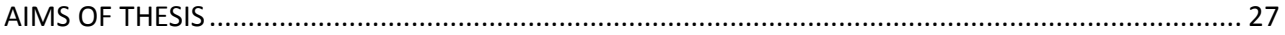

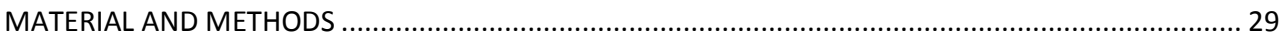

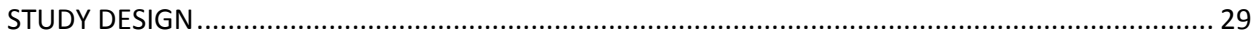

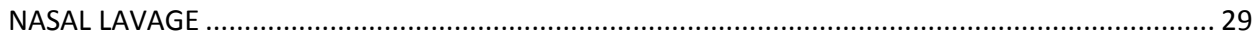

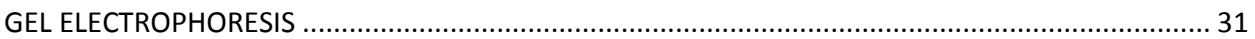

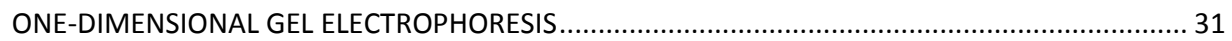

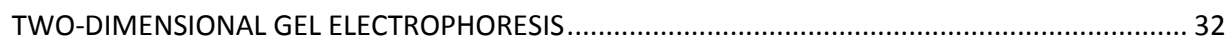

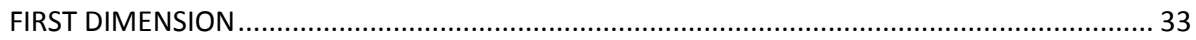

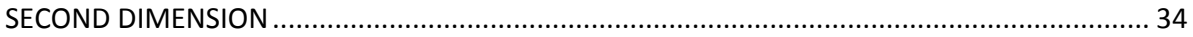

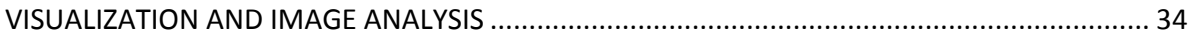

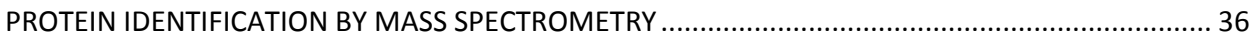

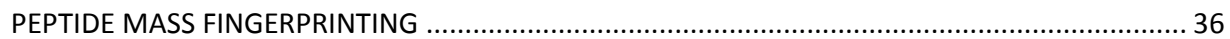




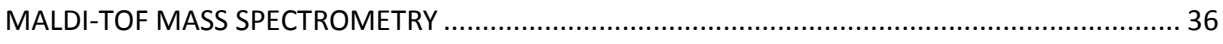

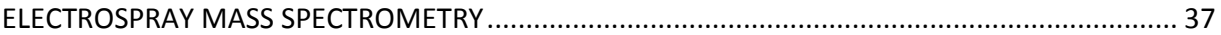

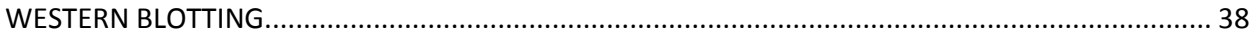

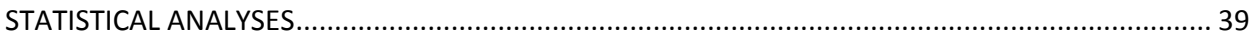

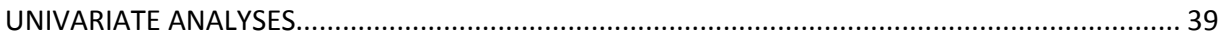

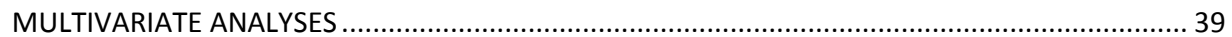

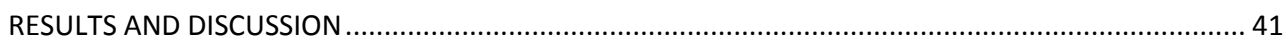

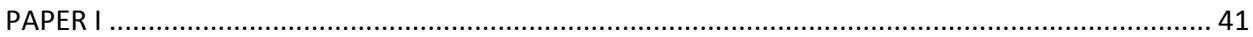

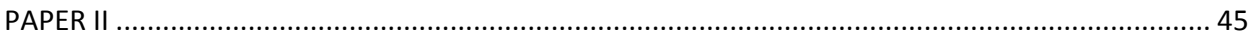

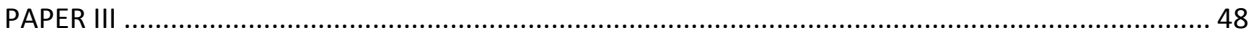

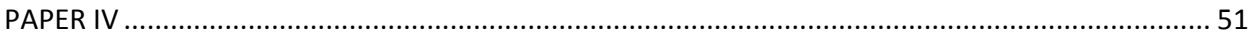

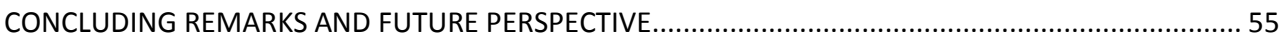

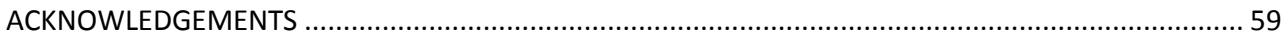

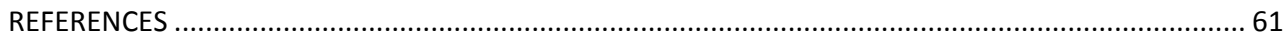




\section{ABBREVIATIONS}

2-DE PAGE

BPI

BPIFA1

CC16

CFTR

COPD

DAMP

ECP

ELISA

$\mathrm{ENaC}$

ESI

IEF

Ig

IL

LPS

MALDI TOF

MS

MS/MS

MWF

NLF

OD

PCA

$\mathrm{pI}$

PLS

RSV

SDS

SP-A

SP-B

SPLUNC1

TLR4

TNF- $\alpha$

WHO two-dimensional polyacrylamide gel electrophoresis

bactericidal/permeability-increasing protein

BPI fold-containing family A member 1

Club (Clara) cell protein 16

cystic fibrosis transmembrane conductance regulator

chronic obstructive pulmonary disease

danger-associated molecular pattern

eosinophil cationic protein

enzyme-linked immunosorbent assay

epithelial $\mathrm{Na}^{+}$channel

electrospray ionization

isoelectric focusing

immunoglobulin

interleukin

lipopolysaccharide

matrix-assisted laser desorption ionization time-of-flight

mass spectrometry

tandem mass spectrometry

metalworking fluid

nasal lavage fluid

optical density

principal component analysis

isoelectric point

partial least square

respiratory syncytial virus

sodium dodecyl sulphate

surfactant-associated protein A

surfactant-associated protein B

short palate lung and nasal epithelium clone 1

Toll-like receptor 4

tumor necrosis factor alpha

World Health Organization 


\section{BACKGROUND}

\section{THE UPPER RESPIRATORY TRACT}

The respiratory tract comprises of an upper and lower part. The upper respiratory tract is composed of nasal cavities, nasopharynx, oropharynx, and larynx, and the lower respiratory tract constitutes of trachea, bronchi, and the two lungs (see Figure 1 for upper respiratory tract anatomy). The upper respiratory tract has several functions; as a heat exchanger, production of speech, carrying stimuli for the sense of smell, and humidifier of inhaled air. In addition to warming and moistening the air, the upper respiratory tract constitutes the first line of defense against particles, such as dust and microorganisms, by filtering the air and possessing an effective, innate immune system. Depending on size, particles are trapped at various levels in the respiratory tract. Large particles are trapped early in the stiff hairs of the nasal vestibule, called vibrissae. Further up, in the nasal cavity, air eddies are formed and smaller particles are thrown out of the stream and trapped to the mucous-covered wall. The mucous is removed by coordinated cilia movement towards pharynx, which is then swallowed. Particles of smaller size get trapped to mucous further down the respiratory tract and removed by ciliated movement on epithelial cells [1].

Once a potentially pathogenic microorganism is trapped to the mucus-covered wall, an innate immune response is triggered. The epithelial cell lining, below the mucus, is a passive physical barrier in itself, but also performs an active function by secreting protective protein compounds into the mucus. These proteins have various antibacterial and proinflammatory functions and are normally present at all times in various concentrations, thereby comprising the initial line of defense. The pathogens that are not cleared by the ciliated cells are removed by the innate immune system primarily through recognition of unique conserved regions on the pathogen surface. This results in activation of Toll-like receptors leading to recruitment of macrophages and neutrophils for phagocytosis, presentation of antigens and initiation of an adaptive immune response [2-3]. A list of mechanisms by which the respiratory tract is protected against pathogens is given in Figure 1. 


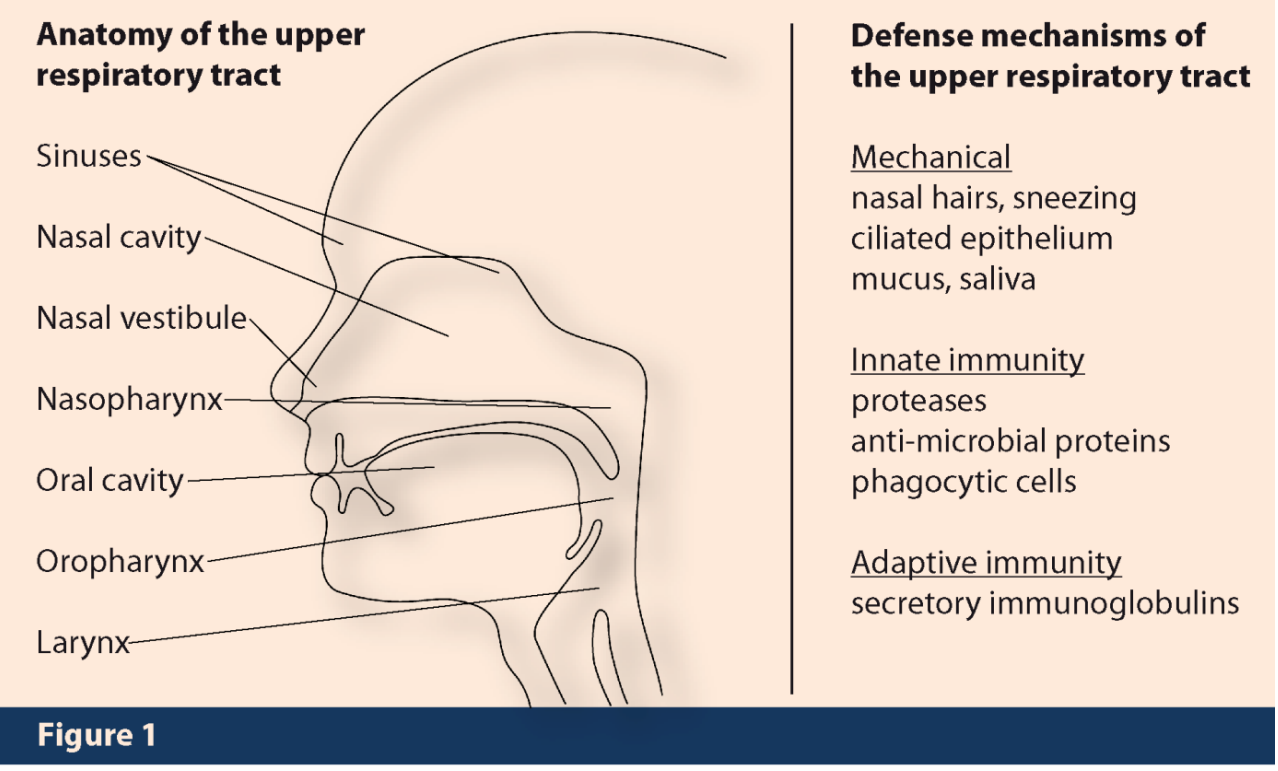

Anatomy and defense mechanisms of the upper respiratory tract.

\section{BIOMARKERS AND PROTEOMICS}

A biological marker, or biomarker, is an indicator of a change in a person due to exogenous or endogenous factors. Bacteria and chemicals are examples of factors originating from outside the body, while a genetic disease like cystic fibrosis is an example of an inner factor [4]. Several definitions of a biomarker are used, the World Health Organization (WHO) define it as "a chemical, its metabolite, or the product of an interaction between a chemical and some target molecule or cell that is measured in the human body" [5]. Biomarkers are widely used in healthcare and research, and are especially important within occupational and environmental medicine, since exposure to substances are frequent issues in this field. Biomarkers can be classified into three types: those of exposure, effect and susceptibility according to the US National Research Council [4]. A biological marker of exposure is defined as an exogenous substance, or its interactive product with the xenobiotic compound and the endogenous components, within the endogenous biological system. A biomarker of effect may be defined as the indicator of an endogenous substance, due to a changed state in the human body that can cause impairment or disease, and also a sign of how well system 
capacity functions. Finally, a biomarker of susceptibility is defined as an indicator that the health of the system is especially sensitive when exposed to a particular xenobiotic compound, in other words, different subjects can react differently to the same compound, due to underlying factors, such as genes or disease [4].

There are also other types of biomarkers, also known as molecular markers of disease, and they can be compared to a biomarker of effect [4]. They are not necessarily dependent on outer exposure, but are instead a sign of disease due to endogenous factors, for example cancer or diabetes. Markers of disease are also measureable in biospecimens and associated with the occurrence or clinical course of a disease. They can be measured both at an early stage as a predictive marker and during the course of disease [6].

A biomarker has certain properties it should fulfill in order to become useful and reliable. Naturally, a biomarker has to be clinically relevant and it has to correlate with the outcome of interest, such as duration of exposure or exposure dose, disease progression or survival. There should be a statistically significant increase or decrease from the normal state of the biospecimen, and the levels should neither overlap between healthy subjects and untreated or exposed subjects, nor vary within the population. Finally, an ideal biomarker should be economical, reproducible, and easily quantifiable in a preferably non-invasive biological fluid or clinical sample [7-9]. A biomarker does not necessarily correlate with the subject's experience of wellbeing; it may be a measure of a state in a subject that has not yet exerted any effect on health [10].

Consequently, it is important to follow a certain procedure when establishing a new biomarker. First, a biomarker needs to be discovered or selected and, ultimately, it should vary consistently and quantitatively with extent to exposure or disease. Validation should follow to establish an accurate relationship between biological change and exposure or disease [4,7]. Also, verification is necessary so several, varying analyses of the same biomarker must demonstrate the same result and statistics will help with final result and sufficient number of incidents [9]. It is essential to have a functioning quality control of practical laboratory procedures later in the process in order to assure accuracy, objectivity and verification of findings [4, 7].

Different ways or techniques can be used to identify new biomarkers, of which the leading approach is proteomics. Wilkins introduced the word proteome at a conference in 1994, as short for "the PROTEin complement expressed by a genOME", to visualize the importance of all proteins expressed in a cell or tissue [11]. When the Human Genome Project was completed, it became clear that the human genome consists of merely $75 \%$ of the anticipated amount of genes [12]. It became apparent that there are more proteins than genes in the human body. The complexity and vast 
quantity of proteins in the human was, however, explained by several start and stop codons on a single gene, generating several, various proteins and post-translational modifications causing an even greater diversity of proteins [13]. In order to manage the vast amount of possible information, and to analyze the proteins and not the genome, proteomics was established. This refers to quantitative, large-scale experimental analysis of proteins that characterizes biological processes and has shown to be very useful in identification of biomarkers [14].

The greatest advantage of proteomics is the opportunity to scan large amounts of proteins, the proteome, in a biological specimen for possible unknown biomarker candidates. In general, proteomics uses two approaches in the discovery phase of biomarkers; gel-based proteomics and gel-free proteomics. Two-dimensional polyacrylamide gel electrophoresis (2-DE PAGE) is used, in combination with mass spectrometry, in gel-based proteomics and constitutes the first step to find potential candidate biomarkers (see Figure 2) [15]. The first dimension separates the proteins in a biological sample by isoelectric focusing (IEF), in other words, the proteins are positioned in a $\mathrm{pH}$ gradient according to their isoelectric point $(\mathrm{p} I)$. This is, in the second dimension, followed by separation according to their relative mass [16]. After image and statistical analysis, candidate proteins are identified with sensitive and precise detection using mass spectrometry. During the discovery phase, a few samples from healthy and exposed subjects are sufficient to acquire the candidate biomarkers. Further downstream, the candidates are tested against large, population-based cohorts to verify and validate findings. In the latter steps it is more efficient to use methods such as enzyme-linked immunosorbent assay (ELISA), western blot or various mass spectrometry-techniques to test the single proteins on a large scale. When choosing a gel-free approach, mass spectrometry-techniques are used early in the discovery phase to identify the candidate biomarkers. This method is also known as shotgun proteomics or bottom-up proteomics, and uses mean analysis of native or proteasederived peptides followed by sequencing with tandem mass spectrometry (MS/MS). The biological sample is often fractioned prior to analysis, due to the complexity of the sample, using different strategies such as chromatography, isoelectric focusing or a combination of both [15]. Proteomics is an expanding field and has become the technology of choice when studying proteins in living organisms and since proteomics developed it has become easier to identify potential new biomarkers. It is of great importance to perform studies on humans that aim to identify biomarkers in order to facilitate diagnosis and healthcare, and so provide improved treatment for patients. 


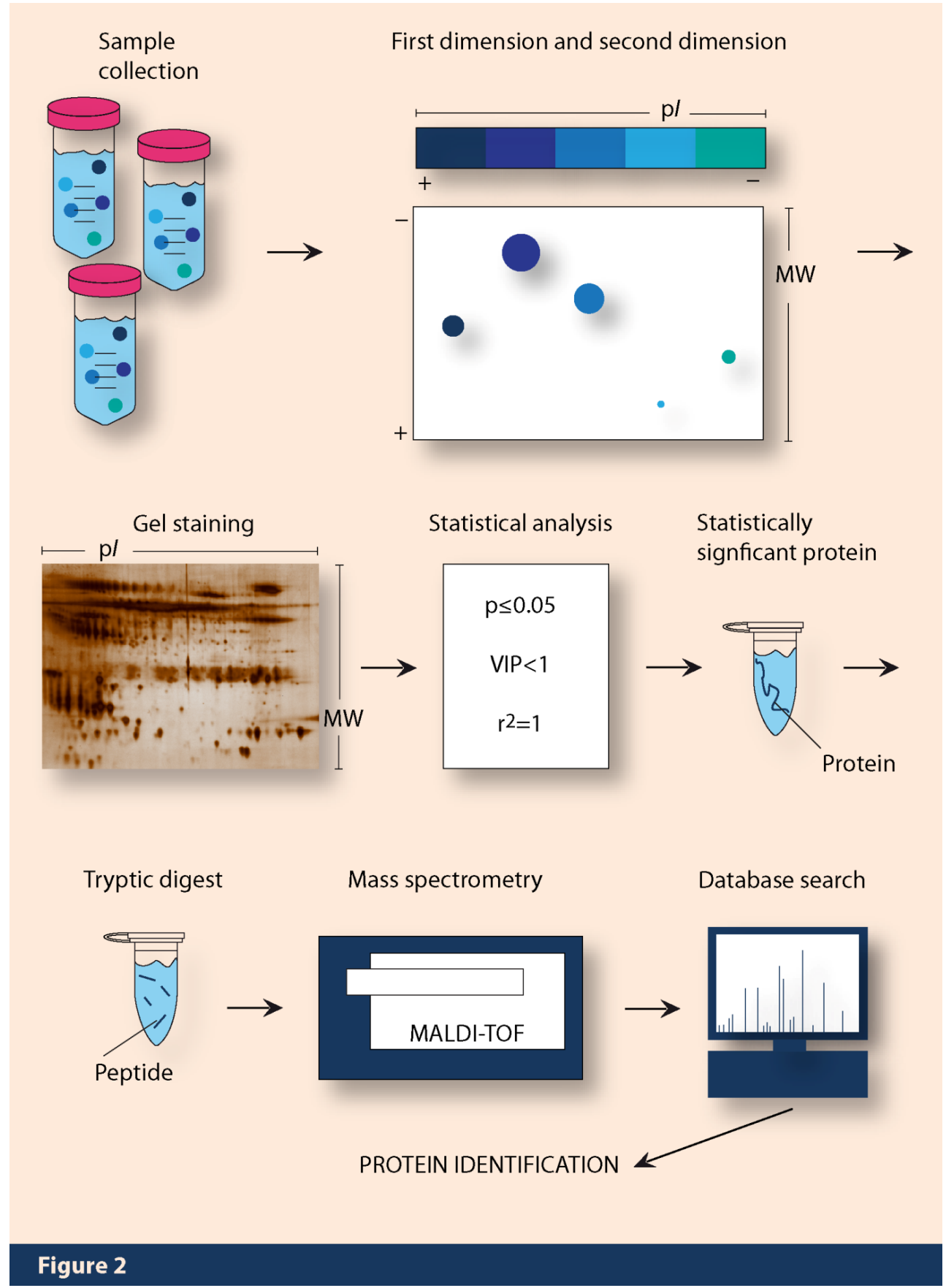

Discovery phase in biomarker research. The figure displays the included steps of a gel-based proteomic approach for biomarker identification using 2-DE PAGE and mass spectrometry. 
Occupational medicine is the medical specialization that deals with issues regarding workers' health, and thereby links work exposure and its condition to their effects on patients. This field of medicine ranges from studying a single worker and his/her problems to studying entire working populations, where one of the most important aspects is prevention of ill health in the work force [17]. Sweden's first occupational clinic started up in the 1940s in Stockholm, although the closely-related environmental medicine was taught at Uppsala University as early as 1725, during the time of Carl von Linné. However, occupational exposure is a well-known issue. Even in the ancient world, Hippocrates described the links between asthma and different occupations, such as metal worker, farmhand and tailor. Today, occupational exposures in regards to chemicals and particles, physical factors, ergonomics at the workplace and psychosocial environment are important issues at the clinics. In order to prevent unnecessary risks and exposures, many occupational areas are controlled by legislation [18-19].

\section{AIRWAY DISEASE IN OCCUPATIONAL MEDICINE}

The respiratory system is vital for our survival and can be divided into upper and lower respiratory tract. The system has many functions; however its primary function is to provide us with oxygen. Airway diseases are common in occupational medicine and different factors contribute to this prevalence i.e. environmental factors, occupational factors and microbial factors. Common environmental exposures are tobacco smoke and radon, especially hazardous in indoor environments, resulting in various respiratory diseases such as asthma, chronic obstructive pulmonary disease (COPD) and lung cancer [20-21]. Also, airborne particulate matter in urban environments is thought to be a cause of mortality in respiratory diseases. Several factors contribute to the increase in particles, for example combustion emissions, mineral dust and wear particles generated by traffic [22].

\section{OCCUPATIONAL EXPOSURES AFFECTING THE RESPIRATORY SYSTEM}

Well-established, occupational exposures include the mineral fibers asbestos and silica or crystalline silicon, which both cause pneumoconiosis - asbestosis and silicosis respectively. All of these conditions are characterized by fibrosis of the lungs. Asbestos is a proven carcinogen and is now banned in most industrialized countries, but is still used extensively in a global context. It has wide industrial applications in, for example, cement products and insulation of wires and pipes. Asbestos is best known for causing malignant mesothelioma, a cancer with a poor prognosis, which has a latency period of 30-50 years [23]. Silica is the most abundant mineral worldwide, where the most common free crystalline form is quartz which is found in sandstone 
and granite. Exposure takes place in many occupations whenever rocks or stones are mechanically broken down and dust which contain crystalline silica is inhaled [24]. Occupational exposure to broadly-defined categories like vapors, gases, dusts and fumes is recognized as increasing the risk of COPD [25]. COPD is defined as a disease state that is characterized by the presence of airflow limitation that is not fully reversible and patients often have a history of chronic bronchitis or occupational asthma [26]. It is believed that by 2030, COPD will be the third leading cause of death worldwide [27]. Cigarette smoke is the primary cause of COPD; nevertheless 15-20\% of all COPD is believed to originate in occupational exposure. One example of occupational exposure is the use of pesticides in agriculture, a sector where $34 \%$ of the global working force is active [25]. Another example is welding fumes, a type of exposure found in many industries [28].

Regardless of whether the exposure is environmental or occupational, microorganisms may also be the underlying cause of airway disease. Waste handlers are daily exposed to various microorganisms, both bacteria and mold, and also lipopolysaccharide (LPS) originating from the cell-wall of Gram-negative bacteria. High rates of bronchial asthma, cough and organic dust toxic syndrome have been reported among waste handlers collecting the organic fraction of household waste [29]. A common consequence due to exposure to microorganisms and organic material is hypersensitivity pneumonitis, which is manifested by shortness of breath, coughing and fever shortly after exposure, caused by inflammation in the alveoli. This is an immunological reaction to an antigen, without the presence of immunoglobulin $\mathrm{E}$ (IgE), but instead the presence of immunoglobulin $\mathrm{G}(\mathrm{IgG})$. A classic diagnosis is Farmer's Lung that is caused by moldy hay or grain [30-31].

It is important to become aware that environmental and microbial factors may be present at a workplace, without necessarily being a result of exposure from the work underway, which may still affect the employee in a negative manner. In others words, environmental and microbial exposure becomes an indirect occupational exposure.

\section{OCCUPATIONAL RHINITIS AND OCCUPATIONAL ASTHMA}

One of the major respiratory diseases affecting employees at the workplace is occupational rhinitis. It is defined in the same way as nasal allergies to common environmental allergens (for example birch pollen) as nasal congestion, sneezing, rhinorrea and itch due to inflammation of the nasal mucosa. The diagnosis, depending on severity, can lead to abnormal sleep, problems in managing work, impairment of daily activities including sport and leisure, and other severe symptoms. Rhinitis may be divided into allergic and non-allergic rhinitis. Allergic rhinitis is mediated via sensitization to a new allergen at the workplace or via exacerbation of a pre-existing condition when the allergen is also present at work. The inflammatory reaction in the 
upper airway mucosa is both antibody and cell-mediated. During the allergic stimulus infiltration of eosinophils, mast cells, basophils and T helper (Th)2-lymphocytes occur and mediate large increases in blood flow [32]. The allergic response can be both IgEand non-IgE-mediated. Most often high molecular weight agents, comprising glycoproteins from vegetal and animal origin, generate an IgE-mediated response whereas low molecular weight agents, for example isocyanates, woods and persulphate salts, cause non-IgE-mediated occupational rhinitis. Also, non-allergic occupational rhinitis occurs which is a response without immunological reaction, even though the same symptoms are present as in allergic occupational rhinitis. Exposure to smoke, vapors and fumes can cause non-allergic occupational rhinitis, and occasionally exposure to high concentrations of irritating or soluble chemicals causes severe forms of rhinitis, with ulcerations and perforation of the nasal septum [33]. In the case of non-allergic occupational rhinitis, reaction may be immediate on first exposure without any latency period [34].

Occupational rhinitis is two to four times more common than occupational asthma [33]. Nevertheless, asthma is a common diagnosis with 300 million people affected worldwide, of which $15 \%$ of all cases are estimated to be work-related [18, 35]. Occupational asthma is characterized by having one or more of these symptoms; decreased airflow, hyperresponsiveness or inflammation. Reaction is caused by the occupational environment and the stimulus is not found outside of the occupational environment. As is the case for occupational rhinitis, asthma is divided into allergic asthma, with high molecular weight agents and low molecular weight agents as induction, and non-allergic asthma [18]. Of the people diagnosed with occupational asthma, 76-92\% are estimated to also suffer from occupational rhinitis [36]. Many studies show that rhinitis is an early stage of asthma, and perhaps even the same disease state, but manifested in either upper or lower respiratory tract or at both sites at the same time.

The phenomenon is referred to as united airways disease. Several pathophysiological factors have been proposed as the link between the upper and lower respiratory tract. For example, when the disease is expressed in either upper or lower respiratory tract it generates a systemic bone marrow-derived inflammatory response affecting the entire respiratory tract. Also, when the nasal mucosa is stimulated by an irritating substance, it may generate bronchoconstriction mediated by a neurogenic reflex [32]. Occupational rhinitis and occupational asthma are a little more complex then common rhinitis and asthma when examining the wide range of sensitizers that may cause the disease. So far, the united airway hypothesis might not be consistent with all occupational sensitizers. Nevertheless, in general, the same mechanisms are thought to occur for these diagnoses as well, supporting the united airway-hypothesis [37-38]. 
As already mentioned, occupational rhinitis may be considered as an early stage or disease, preceding the more severe stage of occupational asthma. However, it is important not to neglect occupational rhinitis, since it represents a diagnosis of its own with substantial impact on sufferers. It is evident that the subject's physiological wellbeing is affected and perhaps even socio-economic issues occur if work productivity is altered. Consequently, it is important to introduce preventive methods at an early stage in order to minimize patient suffering and the development of asthma. Not surprisingly, the most effective intervention is to avoid exposure to sensitizing agent and, when that is not possible, use medical surveillance in order to detect worsening of symptoms [33-34]. In addition to reduce the suffering of patient, early intervention against occupational rhinitis brings substantial financial benefits for both society and the employer.

\section{SWIMMING POOL FACILITIES}

Swimming is considered to be a health-beneficial activity performed as exercise, rehabilitation and for recreation purposes and fun, all over the world. Facilities ranging from one rectangular swimming pool to large water parks can be found. Unfortunately, the swimming pool environment is also connected to respiratory problems [39-40]. Several studies have shown that personnel, especially lifeguards, swimming teachers and technicians who spend substantial time in the indoor swimming pool environment suffer from problems. Pool attendants, life guards and trainers are reported to suffer from symptoms such as eye, throat and nose irritation, coughing, wheezing and chest tightness as well as skin problems [41-44]. In addition to mucosal symptoms, occupational asthma has been reported among employees [45-46]. Besides employees at swimming pool facilities, competitive swimmers spend considerable time in the environment and studies have reported that they experience similar problems with asthma and bronchial hyperresponsiveness [47-48]. However, health effects in recreational visitors and especially in children are more controversial. One study found higher risks of developing asthma and airway inflammation, when adolescents attended outdoor swimming pools [49]. Several studies also indicate that young children who often visit indoor swimming pool facilities have a higher risk of developing respiratory problems such as asthma, increased lung epithelium permeability, recurrent bronchitis and allergy, later in childhood [50-51]. On the contrary, two studies report no correlation between time spent in pool environment and respiratory problems among children. In these studies, the children exposed were not more likely to suffer from lower respiratory tract infection or increased risk of wheeze or otitis media. Instead, positive effects were indicated, with increased lung function and lower risk of developing asthma and allergy [52-53].

In order to avoid spread of infectious diseases among bathers and to keep the pool water clean from dirt and debris from bathers, several techniques are used. In addition 
to methods for filtration, dilution, circulation and bather load, the water is disinfected to avoid growth of microorganisms. Different methods may be used to disinfect the water. Chlorine-based disinfectants are the most common method used, however bromine-based disinfectants, ozone, ultraviolet radiation and, to some extent, algicides can also be used [39]. The most common method of adding chlorine to the pool water is dosed in gaseous form or as sodium hypochlorite. When chlorine $\left(\mathrm{Cl}_{2}\right)$ is added to the pool water, hypochlorite ions $\left(\mathrm{ClO}^{-}\right)$are formed together with hypochlorous acid $(\mathrm{HClO})$, which is a very potent disinfectant and minimize the risk of spread of infectious microorganisms to bathers and employees.

It is clear that the indoor swimming pool environment generates mucosal problems, but the direct cause remains largely unknown. Most studies point to the combination of the hypochlorite ions and hypochlorous acid, which are present in the water for disinfection, with chemical compounds that are formed through reaction with nitrogen containing substances brought to the water by swimmers in form of for example skin, urine, sweat and cosmetics. The reaction generates what is known as disinfection byproducts. Depending on source, various disinfection by-products are formed and among them mono, di and trichloramine [39, 54]. Formation of disinfection byproducts is dependent on water temperature and $\mathrm{pH}$, chlorine concentration, ventilation, bather load and hygiene among swimmers. The solubility of disinfection by-products varies and monochloramine $\left(\mathrm{NH}_{2} \mathrm{Cl}\right)$ and dichloramine $\left(\mathrm{NHCl}_{2}\right)$ are quite water soluble and mostly remain in the water, but may also be released into the air through water droplets or aerosol.

Trichloramine $\left(\mathrm{NCl}_{3}\right)$ is not particularly water soluble, but instead very volatile and transfers to air upon formation, which is enhanced by water turbulence [43]. The typical chlorine smell in swimming pool facilities is caused by trichloramine [55]. Pools for recreational activity, with water slides and fountains are thought to generate higher concentrations of disinfection by-products, and especially trichloramine, due to aerosol formation and therefore also higher prevalence of physiological problems reported from personnel and bathers [54]. Urea, generated from swimmers, is thought to be the primary precursor for trichloramine formation; however other nitrogencontaining compounds have been proposed as precursors for trichloramine formation, for example uric acid [56-57]. Normally, trichloramine is measured close to breathable height above water surface to imitate respiratory exposure [43]. Some of the disinfection by-products that are formed, for example trihalomethanes and haloacetic acids, are regulated by authorities via threshold values. Besides these compounds, WHO has introduced a guideline value for trichloramine for the atmosphere of swimming pool environment to $0.5 \mathrm{mg} / \mathrm{m}^{3}$ [39]. Héry et al proposed the same limit as early as 1995 , but since only a few studies had been made at that point, no official 
guideline was set [54]. Recently, Parrat et al, has proposed $0.3 \mathrm{mg} / \mathrm{m}^{3}$ as exposure limit for Switzerland and a similar level has already been used in France [43, 58].

Efforts have been made to study changes in the respiratory tract among personnel and swimmers, both at a physiological level using spirometry and exhaled nitric oxide, and on a protein level to identify possible biomarkers of airway effects. As already mentioned, trichloramine has low water solubility and therefore easily penetrate into both upper and lower respiratory tract. It can influence the lining cells, as well as the permeability of the lung epithelium. Club (Clara) cell secretory protein 16 (CC16) and pulmonary surfactant-associated protein A and B (SP-A and SP-B) are typical airway proteins that often are measured in serum. Augmented serum levels of SP-A and SP-B have been shown after swimming in chlorinated pools, suggesting increased permeability of the lung barrier [59]. In line, increased plasma levels of CC16, associated with disinfection by-products from the chlorinated water, are shown among swimmers, especially after short-term training [40,60]. However, some studies have instead linked the increase of $\mathrm{CC} 16$ in serum and urine to high intensity training, generating higher permeability in the lung epithelium, thereby enabling leakage to the blood stream [59, 61]. When CC16 was measured in children regularly attending swimming pool facilities, not necessarily under intense training, the levels were instead lowered [62]. One in vitro study showed higher release of interleukin 6 (IL-6) and interleukin 8 (IL-8) from human lung cells exposed to swimming pool air, as compared to cells stimulated with trichloramine alone. This implies that the presence of additional disinfection by-products in the air contribute to the inflammatory response of the respiratory system. Nevertheless, monitoring trichloramine levels and keeping them low may possibly contribute to an overall reduction of all disinfection by-products, thereby indirectly generating a good air environment [63]. Until now, many studies have been made regarding potential biomarkers and effects of indoor swimming pool milieu on swimmers and personnel. Nevertheless, no similar efforts have been made to investigate protein changes in airway samples in connection to irritant exposure at indoor swimming pool facilities.

\section{OCCUPATIONAL EXPOSURE TO METALWORKING FLUIDS}

Metalworking fluids (MWF) are widely used in industry to improve metal properties when machining or grinding. It is foremost used to lubricate and cool the interface between the metal work piece and the cutting edge of the machine tool. Additional features of MWF are prolonged tool life, removal of metal chips formed during machining, improved surface finish, minimization of corrosion and reduction of power consumption. MWFs are complex mixtures that may be divided into four groups: straight (mineral or vegetable oil, not soluble in water), soluble (emulsion with water, mostly oil), semi-synthetic (emulsion with water, a little oil) and synthetic (mixture of 
water and chemicals, no oil) [64]. Water-based MWF, especially synthetic, is thought to have the best properties and is also widely used today.

Exposure to MWFs is associated with occupational problems, partly due to the formation of aerosols that are released into the air. Depending on what type of MWF is used, different problems arise. Dermatological problems are common and mostly associated with straight MWFs, but found among all MWF types. Internationally, the prevalence of work-related dermatoses in metal industries ranges from 4 to $14 \%$. Occupational dermatitis was diagnosed in $14 \%$ of metal workers in one industry in Sweden, and when considering skin manifestations in general, 55\% showed signs [65]. Similar numbers are seen in Finland with $27 \%$ reporting skin disease [66]. Many water-soluble MWFs contain biocides that are formaldehyde releasers, and these are also known to cause contact allergy [67]. MWFs contain many chemicals, of which some may cause cancer. Studies have shown that exposure to straight MWF is associated with increased risk of kidney, bladder and lung cancer, skin tumors and melanoma [68-70].

In addition to skin problems and cancer, respiratory problems are very common and are mostly associated with water-soluble MWFs. Machinists show higher prevalence of common symptoms such as coughing, phlegm, wheezing, chronic bronchitis and rhinitis compared to referents [71-72]. A study in Great Britain, the Shield Surveillance scheme, monitoring causal agents for occupational asthma has shown that MWF is an emerging problem, and in some areas represents the majority of new cases of occupational asthma [73]. It is likely that the various additives are responsible for respiratory problems, whereof several are known to be irritative for example the emulsifiers used to disperse oil in water, chemicals that inhibit corrosion and biocides to control the growth of microorganisms [64]. One study shows how an additive, in this case the corrosion inhibitor tolyltriazole, causes rhinitis [74].

However, the direct cause of the health effects in the industry is often unclear and not correlated to a specific compound. The exposure is complex and chemical reactions over time, influenced by thermal variation can alter the chemical composition in MWF leading to the formation of new substances that may affect the machinist. For example, the biocide 4,4'-methylenedimorpholine is hydrolyzed and released as morpholine [75]. Upon machining, mist or aerosol is spread through the air with dust and particles. Depending on size, particles can be inhaled and reach the alveoli and potentially increase risk of pulmonary injury [76]. Additionally, aldehydes, alkanolamines and volatile organic compounds can give rise to both respiratory and dermal health problems $[66,77]$. For example, alkanolamines are spread through the air and to some extent breathed in, but mostly taken up through the skin [77]. One issue that has been getting more attention is the contamination of microorganisms and the generation of endotoxin during the use of water-soluble MWFs. A wide variety of microorganisms 
have been found where the most commonly-reported microorganisms are aerobic Gram-negative bacteria such as Pseudomonas [78]. Biocides are added to control its growth but are not always sufficiently effective. A study has showed that bacteria can quickly colonize a newly-cleaned, semi-synthetic MWF system. Within hours, almost the same levels of bacteria were found in the new MWF as prior to dumping, cleaning and recharging [79]. Moreover, hypersensitivity pneumonitis is connected to work with MWF. The causative agents for hypersensitivity pneumonitis is debated and no clear understanding can be found in the literature [80]. Reports of Mycobacteriumcontaminated MWF is pointed out as a possible source of hypersensitivity pneumonitis [30], whereas others point out the mist itself coming from MWF [81]. Interestingly, one study report many cases of hypersensitivity pneumonitis even though measured oil mist levels did not exceed recommended values and no specific bacteria could be identified. Best treatment in this case was the use of preventive measures [82].

In order to generate an occupational environment with MWF aerosol values as low as possible and to minimize effects on health, several preventive steps are usually taken. It is of great importance that the machine hall and the actual machine site have sufficient ventilation. For example, enclosing machines can mean lower emission of MWF to air leading to less exposure. Additional measures include protective clothing and the monitoring of MWF quality in order to keep it in good condition. Today, straight MWF is controlled by occupational exposure limits, however water-soluble MWF still lacks established threshold values [83]. Finally, regular medical check-ups of employees can help to identify health effects at an early stage and reduce the number of cases with more severe symptoms. At present, few studies have been performed aimed at identifying specific biomarkers to assess airway effects on humans, and then further verify symptoms in an objective manner [84-85].

\section{DAMP AND MOLDY BUILDINGS}

Low levels of mold and bacteria are found everywhere in the environment and normally do not exert a negative impact on humans. However, under circumstances of elevated humidity in the air or on surfaces, growth can be rapid and it is well known that buildings with high humidity have increased microorganism growth rates. Elevated humidity levels in a building may be caused by several different factors. When the house is constructed, a wet environment can cause humidity to be enclosed and consequently trigger growth of microorganisms. This is especially common in Scandinavian countries where the climate contributes to indoor humidity levels. For example, rain and snow can cause dampness in floor construction due to capillary transportation of water from the soil to the concrete slab or building materials. Other common factors that generate humidity in buildings include ineffective ventilation, malfunctioning air conditioning, leaking drainpipes and when water penetrates the building through walls, windows or roof. Flat roofs are especially sensitive and more 
often generate leaks than buildings with saddle roofs. In addition to sustaining the growth of microorganisms the humidity or water can, by itself, start up chemical processes with the surrounding environment which degrade building materials and generate emissions of compounds capable of affecting people. This process occurs parallel to the growth of microorganisms. Buildings affected by the above-mentioned problems are sometimes referred to as sick buildings [86-87].

Many compounds and emissions are known to contribute to the indoor environment. In many houses it is common to find nitrogen dioxide, carbon monoxide, particulate matter, tobacco smoke, volatile organic compounds and biological matter. In extraordinary conditions, high levels exert a negative impact on residents' health. In relation to damp and moldy buildings, emissions from building materials and furniture in the form of volatile organic compounds have been found to be important components [88]. Degradation of the plasticizer di(ethyl-hexyl)-phtalate (DEPH), which is found in polyvinyl chloride (PVC) floor coatings or carpet glue, generates emissions of ammonia and 2-ethyl-1-hexanal that are both found to exert an irritating effect on mucosal membranes [87, 89]. The combination of polyvinylchloride floors and adhesives generates more volatile organic compounds than polyvinyl chloride floors alone [90]. Wooden material emits hexanal, $\alpha$-pinene and $\Delta(3)$-carene and are found to be irritating for the respiratory tract at high levels [91]. Also, microorganisms generate emissions of volatile organic compounds which are then referred to as microbial volatile organic compounds. One of the most common compounds is 3methyl-1-butanol (3MB), although no clear effect has been found on humans [92]. Another microbial volatile organic compound is 1-octen-3-ol that has been associated with home-related mucous symptoms [93]. This shows the importance of maintaining a proper indoor environment, as it minimizes the risk of building-related airway problems. However, when a building is found to be damp or moldy, it is important that steps are taken at an early stage to halt the process and prevent residents from becoming ill (or more ill). Samples to test for possible presence of microorganisms, both in air and on surfaces should be taken and measurements of air humidity, temperature and air movement performed. In moderate cases, a thorough cleaning and a ventilation check-up may suffice and in more severe cases large-scale renovation or even demolition of buildings may become necessary [86].

The links between medical symptoms and exposure to damp and moldy buildings are unclear and in many way complex [94]. Today no established diagnosis exists. Nevertheless, exposure to mold and damp buildings is associated with symptoms from mucous membranes, generating symptoms from eyes and upper and lower respiratory tract, as well as dry skin, headaches and lethargy. The overall condition is sometimes called Sick Building Syndrome in Europe, or building-related illness in United States [86]. Studies have shown that a moldy workplace environment is associated with a 
13\% increased risk of aggravated asthma and development of new asthma [95]. This will, in the long run, result in impaired work ability and in the worst case a withdrawal from work [96]. A similar result has been shown among habitants of dwellings where 5\% developed asthma after living in damp and moldy homes [97]. Another study showed the presence of rhinitis among adult habitants in moldy dwellings [98]. In addition to rhinitis and asthma, general nasal symptoms such as irritated, stuffy or runny nose, have been shown together with other mucosal symptoms, such as coughing, hoarseness and dry throat and irritated eyes [93].

A group of people commonly affected by this type of indoor problems are those working in office buildings, schools, hospitals or day care centers [86]. Up to $30 \%$ of new or renovated office buildings are associated with impaired health [99]. Apart from the above-mentioned factors, female gender, stress, lower status in the organization, low job control, low job support in general, paper dust and working on more routine tasks contribute to the increase of symptoms [86, 100]. Often, the presence of symptoms at a workplace varies greatly among the employees, with only some affected. It is not uncommon that employees show symptoms without any known building-related problem present. This illustrates how important the psychosocial environment and the individual perception are to the indoor environment and experienced health status [101-102]. Thus, microorganisms or chemical compounds do not need to be involved in the development of building-related problems, even though it is a common situation.

Since symptoms arising after prolonged stay in damp, moldy buildings are complex and sometimes vague, it is necessary to find objective ways to verify the health status of the individuals affected. In order to investigate workplaces with the possible presence of building-related airway problems, the most common line of action is to administer questionnaires but acoustic rhinometry (measuring nasal patency) and ocular function test (measuring tear film stability) is common [94, 103]. Studies have tried to identify specific biomarkers to assess airway effects and further verify symptoms. For example, one study in a damp, moldy office building found elevated levels of endotoxin to be associated with higher levels of the nasal markers eosinophil cationic protein (ECP) and IL-8. Blowing out thick mucus was associated with fungi and glucan [104]. In other studies, the inflammatory cytokines IL-1, IL-6 and tumor necrosis factor- $\alpha$ (TNF- $\alpha$ ) were found elevated in nasal lavage fluid in subjects working in moisture-damaged schools and the protein lysozyme was found to be elevated in hospital workers $[89,105]$. Further, a longitudinal study of damp, moldy workplace buildings showed increased incidence, and decreased remission of, building-related problems. Also higher levels of ECP and increased bronchial responsiveness were associated with dampness and molds [106]. In spite of the above- 
mentioned studies, there is still a need for more specific and verified biomarkers to facilitate diagnosis and provide better treatment for patients in the healthcare system.

\section{RESPIRATORY SYNCYTIAL VIRUS}

Respiratory syncytial virus (RSV) is by far the most common viral cause of severe respiratory tract infection among infants and young children. Each year, 33.8 million children below five years of age are infected by RSV. Of these, 3.4 million require hospitalization due to more severe infection. In 2005, 66 000-199 000 children below five years of age died from RSV-associated infection and 99\% of these deaths are localized to developing countries [107]. RSV is very contagious and has annual outbreaks during winter time in temperate climates and during rainy season in tropical climates [108]. When children turn two years of age, $80 \%$ are estimated to have had RSV infection and two thirds in the first year of life [109]. RSV normally gives upper respiratory tract infection with symptoms such as rhinitis, cough, coryza and some fever. One third of those infected also contract otitis media. Unfortunately, it is quite common to develop lower respiratory tract infection with accompanying bronchiolitis. The lower respiratory tract infection gives dyspnoea, subcostal recession, feeding difficulties, wheezing, cough and shortness of breath [108]. Of children below five years of age with lower respiratory tract infection, $10 \%$ require hospitalization and are then often referred to as acute lower respiratory tracts infection [109]. Of the children admitted to hospital, $40 \%$ also suffer from a bacterial co-infection, thereby worsening the symptoms and to some extent explaining the high mortality rate [110]. Today, RSV infection is also becoming more recognized as an important pathogen of the elderly, above 65 years of age, with mortality rates comparable to influenza A virus infections [111].

Due to high incidence and mortality rates, many studies have been made on risk factors for infection with RSV. Many risk factors have been recognized where the most important one is young age, with age below one year and also less than 6 weeks of age. Additional risk factors include being born under the first half of the RSV season, low birth weight, crowding and siblings, day care attendance and male gender. Common risk factors such as having parents with low socioeconomic status, passive smoke exposure and no breast feeding have also been shown [112]. Why male gender is a risk factor is not clear, but shorter and narrower airways as well as a stronger eosinophil response compared to girls have been suggested [112-114]. In addition to contracting a RSV infection and bronchiolitis as a young child, there is also a higher risk of developing asthma, allergies and allergic sensitization later in childhood for 
children of both male and female genders. Also non-asthmatic children, with a history of bronchiolitis, have impaired lung function compared to children without a history of bronchiolitis [115]. The effect is seen up to 18 years after point in time of infection [116]. Whether the RSV infection directly contributes to the higher risk of asthma and allergy is debated: one study suggests that RSV infection is an indicator of genetic predisposition to asthma [117].

The pathological mechanisms during RSV infections are still not fully understood and there is an important gap in knowledge about the immune response against RSV in infants. The virus belongs to the family Paramyxoviridae, orders Mononegavirales, and is an enveloped, non-segmented negative-strand RNA virus. It comprises of 10 genes encoding for 11 proteins with two characteristic surface proteins; the $\mathrm{F}$ and highly glycosylated G-protein. The two proteins are thought to be the major targets for antibody response from the adaptive immune system. Normally the virus is confined to the respiratory mucosa and does not spread to other organs in the body. When the infection resides in the upper respiratory tract, the virus predominantly infects superficial ciliated cells, especially in the nasopharynx. In cases where the infection has spread to the lower respiratory tract, the epithelium of the bronchioles and type-I alveolar pneumocytes are infected [109]. Susceptibility to RSV bronchiolitis has been shown to be associated with genes highly expressed during innate immune reaction [118]. RSV is thought to influence innate immunity by decreasing viral defense by reducing production of cytokines and altering the antigen-presenting cell function and consequently making it easier for bacterial co-infections [109]. Studies suggest that the virus also attenuates the production of antibacterial proteins, simplifies the binding of bacteria to the respiratory epithelium and increasing host sensitivity towards pathogenassociated molecules, for example lipopolysaccharide [119-121]. Additionally, the virus does not generate a sufficient adaptive immune response in neither child nor adult, leading to repeated infections throughout life [109].

Ribavirin, an anti-viral drug, has limited efficacy against RSV and the humanized monoclonal antibody palivizumab (Synagis), against the F protein of RSV, is used prophylactically for infants at high risk. Palivizumab only protects against severe disease and does not have an effect on infants with active infection [109]. More proper and specific treatment against RSV is required and a vaccine is desperately needed. In the first months of life, infants have some protection from RSV from maternal antibodies. But after 4 months of age the maternal antibodies have waned and a vaccine is needed. Unfortunately, vaccine development against RSV has proven to be challenging due to the immature adaptive immune system in both neonatal and older infants, meaning that a vaccine needs to be more immunogenic than natural RSV. Vaccines are currently under development by pharmaceutical companies and it remains to be seen if they are successful $[109,122]$. Nevertheless, RSV still lacks 
specific treatment and an effective vaccine indicating the vital importance of a better understanding of RSV infection in all areas.

\section{PROTEINS OF THE NASAL MUCOSA}

The nasal mucosa, as mentioned above, is a part of the respiratory tract but is also included in the first line of defense where it helps to regulate both the innate and adaptive immune system [123]. The nasal mucosa is continuous from the skin in the nostrils and back to the pharynx. It comprises a layer of mucus, followed by ciliated columnar epithelial cells with goblet cells and entrances to submucosal glands in between. Below the epithelium there is a basement membrane, smooth muscle, blood vessels and nerves, and finally a cartilaginous layer [1]. The mucus layer is about 15 $\mu \mathrm{m}$ thick and comprises of two layers; the lower thin sol layer, also referred to as airway surface liquid that is more aqueous and allows the cilia on the epithelial cells to beat and the thicker mucus layer that possesses the property of trapping particles. The goblet cells and submucosal glands produce mucus covering the entire nasal mucosa membrane where it acts as a barrier against foreign particles and microorganisms that attempt to penetrate, as well as protection for underlying cells and conditioning of inhaled air [124]. Even though it stops the entry of foreign particles, it must allow diffusion of molecules between the cells and into the mucus. The mucus is an aqueous mixture of glycoproteins, mostly made up of mucin-type glycoproteins, also known as mucins, divided into two types; the membrane bound and the secreted. The mucus consist of 95-99.5\% water and mucins, but also other proteins, lipids, electrolytes, salt and mucopolysaccharides. The long glycoproteins have two major properties that stop particles from intruding into the epithelial layer; the shape of the glycoproteins forms a net that stop larger particles from entering, and its surface properties that determine if a particle will intrude or become trapped in the mucus by, for example, hydrophobic forces or specific binding interactions [125].

In addition to glycoproteins, many other proteins and immunoglobulins are present in the mucus in order to defend the host against invading pathogens. The proteins are expressed by the epithelial cells and goblet cells, but also by immune cells such as neutrophils, macrophages, eosinophils, denditric cells and B and T cells, present at site during inflammatory states. Many of these proteins show antimicrobial activity. Lysozyme is a protein secreted into the nasal mucosa by nasal glands which carries out antimicrobial activity by enzymatically degrading the bacterial cell wall. Further, lactoferrin is a common antimicrobial protein that works mainly in two ways; by binding up free iron, which is an important nutrient for bacteria, and causing lysis by 
binding to the surface of the microorganism. This protein may also have the ability to regulate granulocyte production and act as a macrophage colony-stimulating factor [126].

During inflammatory responses, infiltrating granulocytes are not only harmful to pathogens but also contribute to tissue damage. Alpha-1-antitrypsin is an important protein for airway tissue protection by inhibiting elastase that is released excessively by neutrophils during inflammatory and infectious states [127]. Another example of tissue-protecting proteins are cystatins that protects inflamed tissue by inhibiting cysteine peptidases [128]. Most of the antimicrobial proteins in the mucosa are part of the innate immune response, but also proteins more associated with the adaptive immune system are present. Immunoglobulin $\mathrm{J}(\mathrm{IgJ})$ and $\beta 2$-microglobulin are important proteins that are necessary for the formation of the antigen-recognizing immunoglobulins $\mathrm{M}(\operatorname{IgM})$ and A (IgA), respectively [129-130]. There are also other important proteins present in the mucosa, even though they do not perform any directly immunological activity. For example, albumin is a transport protein carrying various substances to the site and a regulator of osmotic pressure. It is abundant and constitutes about $40 \%$ of the protein content in extracellular fluid [131]. Many of the proteins are present under physiological conditions to maintain a healthy environment for the nasal mucosa and also because of the never-ending flow of microorganisms inhaled. However, during inflammatory or infectious states the balance is changed and some proteins are increased or decreased to adjust to the particular needs of the host. These changes can be measured by analyses of nasal lavage fluid and the possibility to survey differences is of interest for diagnostic purposes, to understand disease mechanisms and to improve treatment.

\section{PROTEIN S100A8 AND PROTEIN S100A9}

The S100 family, also known as calgranulins, comprises more than 20 small proteins that have a wide range of both intra and extracellular function. They all have two EFhand domains that can bind calcium and the possibility of forming dimers. On calcium binding, the complex becomes activated and binds other targets with various functions [132]. Two members of the family, protein S100A8 (also termed MRP8) and protein S100A9 (also termed MRP14) are expressed in granulocytes, monocytes and early differentiation states of macrophages. Protein S100A8/A9 plays both intracellular and extracellular roles. These two proteins can constitute up to $50 \%$ of the soluble cytosolic content of granulocytes and play an important role in homeostasis mainly by regulating the cytoskeleton [133]. They are often found in high levels as a heterodimer, known as calprotectin, in extracellular fluids during inflammatory diseases such as chronic inflammatory bowel disease or rheumatoid arthritis, but also in various cancers and recently as a biomarker of coronary diseases [133-134]. Interestingly, an important extracellular function of S100A8/A9 is its proinflammatory 
role where it acts as danger-associated molecular pattern molecule (DAMP). By binding to receptors, such as Toll-like receptor 4 (TLR4), it enhances lipopolysaccharide-induced production of cytokines and stimulates granulocytes upon infection with Gram-negative bacteria [135]. The S100A8/A9 complex is also involved in amplifying inflammatory responses by binding to endothelial cells leading to induction of inflammatory cytokines and adhesion molecules on the cell surface [133]. Protein S100A8 plays an antimicrobial role via radical scavenging and binding of zinc ions, thereby depriving a nutrient from bacteria and fungi [136]. Both the heterodimer calprotectin and both proteins on their own play an evident role in inflammation and comprise excellent examples of potentially useful biomarkers in the upper respiratory tract.

\section{SPLUNC1}

The short palate lung and nasal epithelium clone 1 (SPLUNC1) gene was first identified in mice and shortly afterwards the human protein was isolated in nasal lavage fluid by Lindahl et al [137-139]. Over the years SPLUNC1 has had many names, up until 2011 when a new systematic nomenclature for the PLUNC family and its relatives were introduced. SPLUNC1 is now formally known as BPI foldcontaining family A, member 1 (BPIFA1), even though SPLUNC1 is still in use in the scientific world. The family is composed of 8 authentic genes and 3 pseudogenes within the human locus, where SPLUNC1 is localized to chromosome 20q11.2 [140]. SPLUNC1 belongs to the BPI fold containing family (BPIF) that is divided into family A and B, each family consists of 4 and 7 proteins, respectively. Family A was earlier called short PLUNC and is approximately 250 amino acids long and family B was called long PLUNC and is 450 amino acids long. They share sequence and structure similarity to the lipid-transfer protein family that consists of BPI (bactericidal/permeability-increasing protein), LBP (lipopolysaccharide-binding protein), CETP (cholesteryl ester-transfer protein) and PLTP (phospholipid-transfer protein).

The BPI fold containing family A and B is named due to their domains, or folds, that are structurally similar to the domains of the protein BPI, where family A has a similar $\mathrm{N}$-terminal domain and family $\mathrm{B}$ has both the $\mathrm{N}$-terminal and $\mathrm{C}$-terminal domains in common with BPI [141]. The tissue-distribution of the PLUNC family gene expression is limited to the upper respiratory tract. SPLUNC1 is found exclusively in serous cells in the respiratory tract where it is most abundant in the upper part followed by a progressive decrease further down to the lungs. Serous cells are found in the airway epithelium, submucosal glands and secretory ducts [142-143]. However, one study claims to have found SPLUNC1 in the granules of neutrophils, but this has not been verified elsewhere [144]. 
Several studies have shown the involvement of SPLUNC1 in various clinical states and diseases. Levels of SPLUNC1 are lower in subjects with seasonal allergic rhinitis, subjects exposed to cigarette smoke and in workers exposed to epoxy chemicals [137, 145-146]. Similar results are seen in subjects with chronic rhinosinusitis and nasal polyps [147-148]. SPLUNC1 has also been shown to enhance recruitment of leukocytes and elevate phagocytic activity in the lungs of mice after exposure to carbon nano tubes, but in the same time reduce the subsequent chronic inflammation [149]. In addition, mouse studies suggest that SPLUNC1 inhibits eosinophil activation and allergic inflammation [150]. In malignancies, expression of SPLUNC1 has been shown at other sites compared to the normal tissue distribution. This is most likely due to the state of differentiation or the malignant cell type [151]. For example, SPLUNC1 has been identified in gastric cancer and non-small cell lung cancer where SPLUNC1 is proposed as a potential diagnostic biomarker [152-153].

The role of SPLUNC1 is not fully known. Originally it was proposed that SPLUNC1 was involved in host defense of the upper respiratory tract and that it might be a part of innate immunity. That was mainly due to its resemblance to BPI of the same protein family. BPI is primarily released from granules of neutrophils at inflammatory sites. The protein is highly antimicrobial against Gram-negative bacteria and acts antiinflammatorily by binding to lipopolysaccharide to neutralize it [154]. When SPLUNC1 was shown to bind lipopolysaccharide, its involvement in innate immunity was strengthened [155-156]. A later study finally verified the structure of SPLUNC1 and could show a cavity, similar to the cavity of BPI, for the binding of lipids. However, SPLUNC1 was shown not to bind lipopolysaccharide, but instead other types of lipids, such as sphingomyelin, phosphatidylcholine and dipalmitoylphosphatidylcholine, also important in the innate immune system [157]. Over time its antimicrobial function has been supported by several studies. They have shown both in vitro and in vivo how SPLUNC1, in a dose-dependent manner, reduced the growth of several Gram-negative bacteria such as Mycoplasma pneumoniae, Pseudomonas aeruginosa and Klebsiella pneumoniae [158-160]. Further, SPLUNC1 is shown to disrupt biofilm formation of Pseudomonas aeruginosa and Klebsiella pneumoniae by reducing surface tension $[159,161]$. One study also showed antiviral activity against Epstein Barr virus [162]. Altogether, these studies confirm an antimicrobial role of SPLUNC1.

Lately, two new roles for SPLUNC1 in the upper airways have been proposed. First, studies have shown that SPLUNC1 may act as an extracellular inhibitor of ENaC (epithelial $\mathrm{Na}^{+}$channel) that regulates airway hydration and mucus clearance in the airways by $\mathrm{Na}^{+}$absorption. It is primarily regulated through intracellular second messengers but may also be regulated by extracellular serine proteases such as trypsin or neutrophil elastase. SPLUNC1 is now thought to be an additional extracellular 

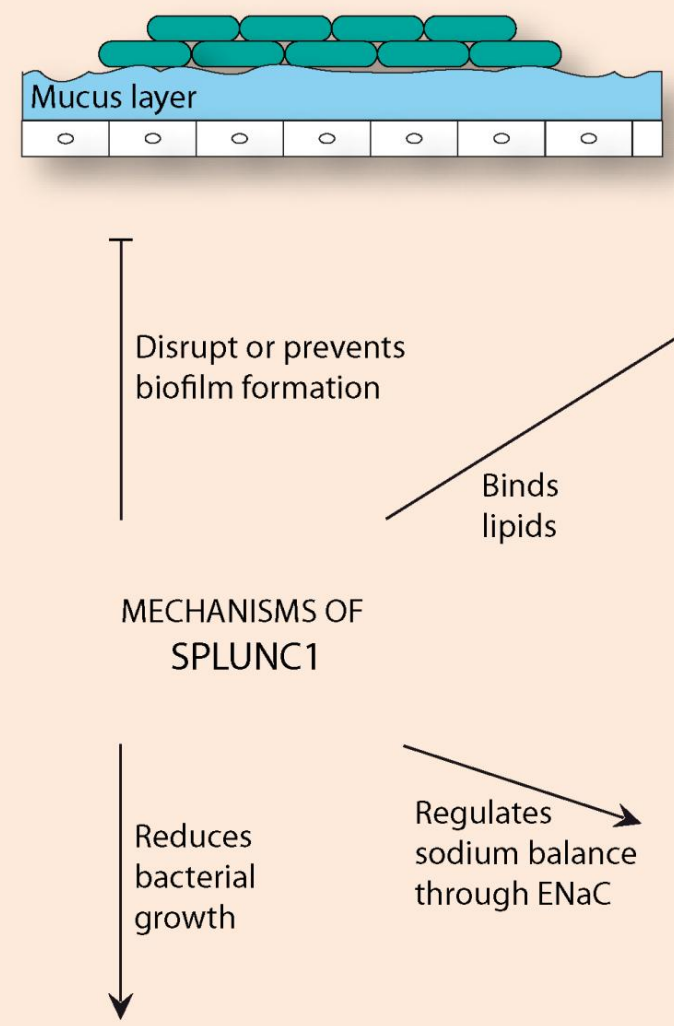

\section{Binds}

lipids
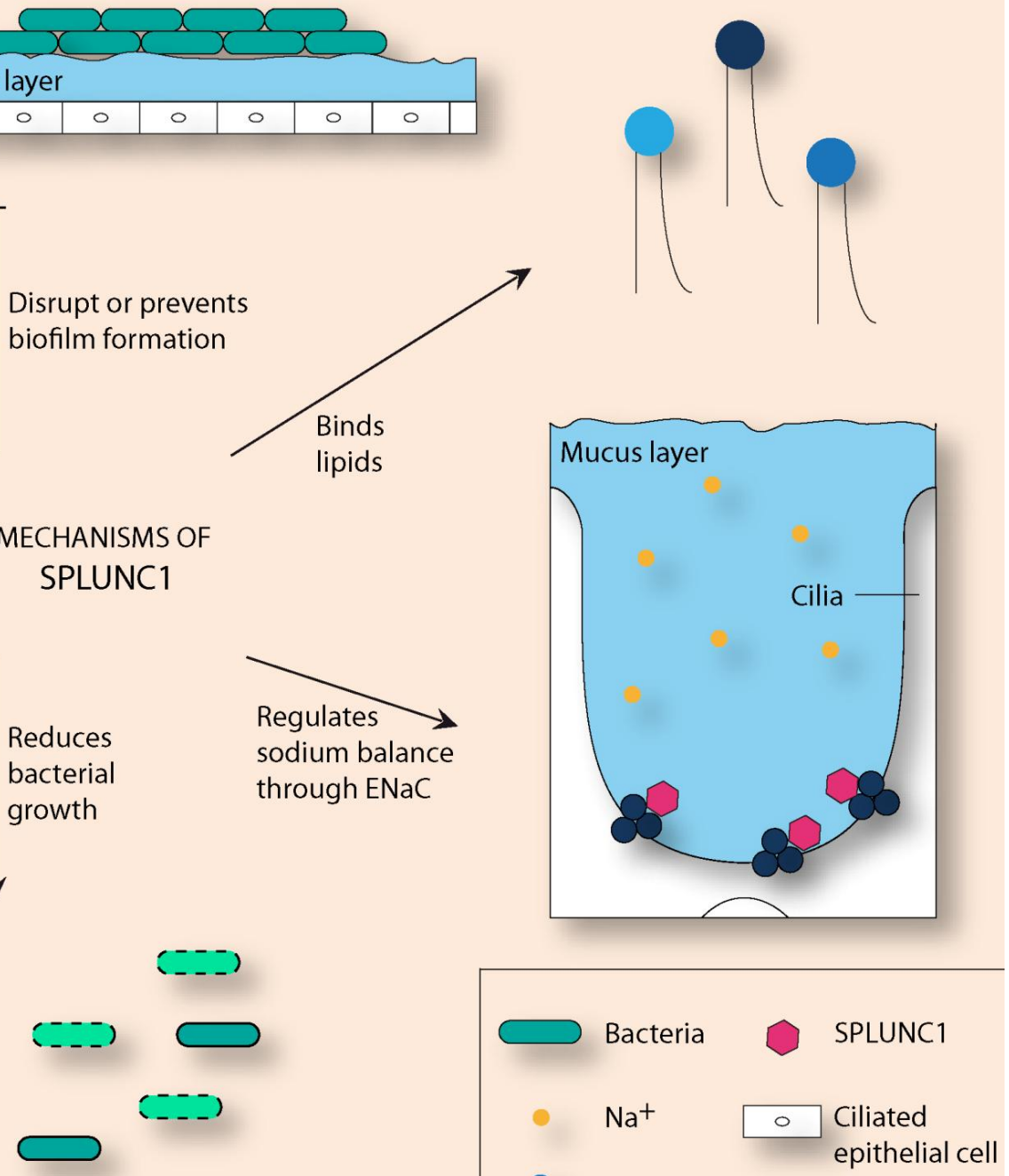

Lipid

$\mathrm{ENaC}$

\section{Figure 3}

Proposed roles of SPLUNC1 in the airways.

molecule whose dilution or concentration in the mucus, or air surface liquid, can adjust the activity of $\mathrm{ENaC}$. The thickness and volume of the mucus in the airways are dependent by the balance of $\mathrm{Na}^{+}$and $\mathrm{Cl}^{-}$, which are regulated through $\mathrm{ENaC}$ and CFTR (cystic fibrosis transmembrane conductance regulator), respectively [163]. In 
cystic fibrosis, CFTR is absent leading to hyper activity of ENaC and an excessive absorption of $\mathrm{Na}^{+}$. The air surface liquid then becomes thinner and thicker in texture leading to impaired cilia beating and less mucosal transport [164]. SPLUNC1 is also thought to reduce the number of ENaCs on the epithelial cell [165]. In cystic fibrosis, low $\mathrm{pH}$ in the mucus is thought to reduce SPLUNC1 function and thereby enhance the high activity levels of $\mathrm{ENaC}$ and the dehydration of the mucus. This promotes invasion of microorganisms and chronic lung infections [166]. In its second role, SPLUNC1 is proposed to share similar properties to latherin, a protein found abundantly in horse sweat that has potent surfactant properties at the air/liquid interface. Surfactant is a vital liquid in the lower respiratory tract where it helps to keep the alveoli open, but it is also found in the conducting and upper airway where its function is not fully understood. Probably, its primary role is to disrupt or prevent biofilm formation from bacteria and SPLUNC1 is therefore hypothesized to have a dual role in the microbial defense, both as surfactant and by antibacterial activity [167]. A compilation of SPLUNC1's proposed functional roles is seen in Figure 3.

Our understanding of the role of SPLUNC1 and other innate immune proteins in the upper respiratory tract is still incomplete. Increasing our knowledge of these proteins might aid in identifying shared disease mechanisms in infections and in other respiratory diseases, which may be affected by exposure to irritative chemicals. This would mean that they would serve not only as reliable biomarkers, but also provide clues as to potential therapeutic targets. 


\section{AIMS OF THESIS}

Exposure to irritative and microbial agents can cause upper airway mucosal inflammation and give rise to an altered protein composition. The overall aim of this thesis was to characterize such alterations in the upper airways with a proteomic approach to identify potential biomarkers and provide new insights about the inflammatory effects.

The specific aims of the papers included were as follows:

- To investigate the presence of SPLUNC1 and other innate immune proteins in nasopharyngeal aspirates associated with respiratory syncytial virus infection (Paper I).

- To explore the occurrence of airway symptoms among personnel working at swimming pool facilities in relation to trichloramine exposure and protein changes in nasal lavage fluid (Paper II).

- To evaluate the association between exposures from water-based metalworking fluids and the health outcome among industry workers and to assess changes at a protein level in the nasal mucous membranes (Paper III).

- To identify effects on the upper airway mucosa after work in moldy and damp buildings and to identify and measure possible protein biomarkers in nasal lavage fluid (Paper IV). 


\section{MATERIAL AND METHODS}

\section{STUDY DESIGN}

In Papers II-IV we have used a similar approach as concerns study design and work process. A cross-sectional study approach has been used. Cross-sectional studies measure exposure or disease at a given point in time or within a short time frame and aim at describing a population or a subgroup [168]. The purpose is to find the prevalence of the outcome of interest and because the sample is usually taken from the entire population, it is possible to estimate the correct prevalence. Cross-sectional studies do not presuppose from a hypothesis, but rather generate hypotheses for future research since this is a descriptive study design that indicates associations that may exist. As there is no way of knowing, for example, exposure rates before or in the future it is impossible to infer causality. Also, the results only reflect the selected time point. A representative sample is also important when using questionnaires to avoid biased answers, as well as having a high response rate to be able to draw correct conclusions [169-170]. All our studies were initiated with questionnaires and exposure measurements at site of study. Either an in-house questionnaire or the standardized questionnaire MM $040 \mathrm{NA}$ has been used in order to explore physical and psychological wellbeing experienced, as well as perceived indoor environment among participating subjects [171]. Simultaneously, biological samples from subjects were obtained, most often nasal lavage fluid but also exhaled nitric oxide and blood samples, for allergy tests. Methods chosen are described in more detail further on.

NASAL LAVAGE

The upper airway mucosa comprises the first encounter for inhaled irritants and microbial agents and the mucosa responds by changing its expression of proteins and 
cells. These changes are of interest to measure in order to understand the humoral pathophysiological response, provide early diagnosis and understand the action of the inhaled agent. One way to measure changes are by using nasal lavage, which is a noninvasive sample technique that also demonstrates the nasal mucosa in a representative manner. The fluid contains excretions from goblets cells and seromucous glands, including epithelial cells and immune active cells, and last plasma exudation that is possible to measure [172-173]. Changes in nasal lavage fluid have been shown in studies of exposure to organic acid anhydrides, wood dust and indoor environmental perception, and in disease states such as allergy, cystic fibrosis and asthma [145, 173176]. One study reports the use of nasal lavage fluid as an alternative to the more invasive bronchoalveolar lavage to monitor early lower airway inflammation in cystic fibrosis [177].

There are different ways of collecting nasal lavage fluid; dilution techniques (for example nasal lavage), nasal-spray washing or absorption on cotton wool and rubber foam sampler [178-179]. Nasal lavage is the most commonly-used method for sampling proteins and other components from the upper airways. At present no standardized methods exist making it difficult to fully compare studies. Room tempered isotonic saline solution was used that was instilled by a Foley catheter into the nasal vestibule while the subjects flexed their heads at a forward angle to avoid swallowing. The solution was maintained in position for 5 minutes before being withdrawn and analyzed (see Figure 4). Nasal lavage material contains cells, soluble components, lipids and proteins. There are different parameters that can influence the results of the nasal lavage. Studies have shown that time of day, duration of solution in the vestibule, temperature of the solution, performing pre-washing or not, number of repeated measures each day and days in a row may all influence the results gained [173, 180-181]. The concentration, volume and presence of various markers may be altered due to these factors and consequently they are significant to consider when performing a study. Also, the management of the samples is important to consider since repeated freeze-thaw cycles, proteases and storage temperatures may influence the end result $[173,179]$. Nevertheless, the intra-individual variation is lower than the inter-individual variation, making it possible to follow a subject over time to study possible alterations [179]. Furthermore, nasal lavage is useful and informative in the sense that it is possible to see protein alterations and magnitude of inflammation in the upper airways, as well as an uncomplicated method for sample collection at workplaces. 


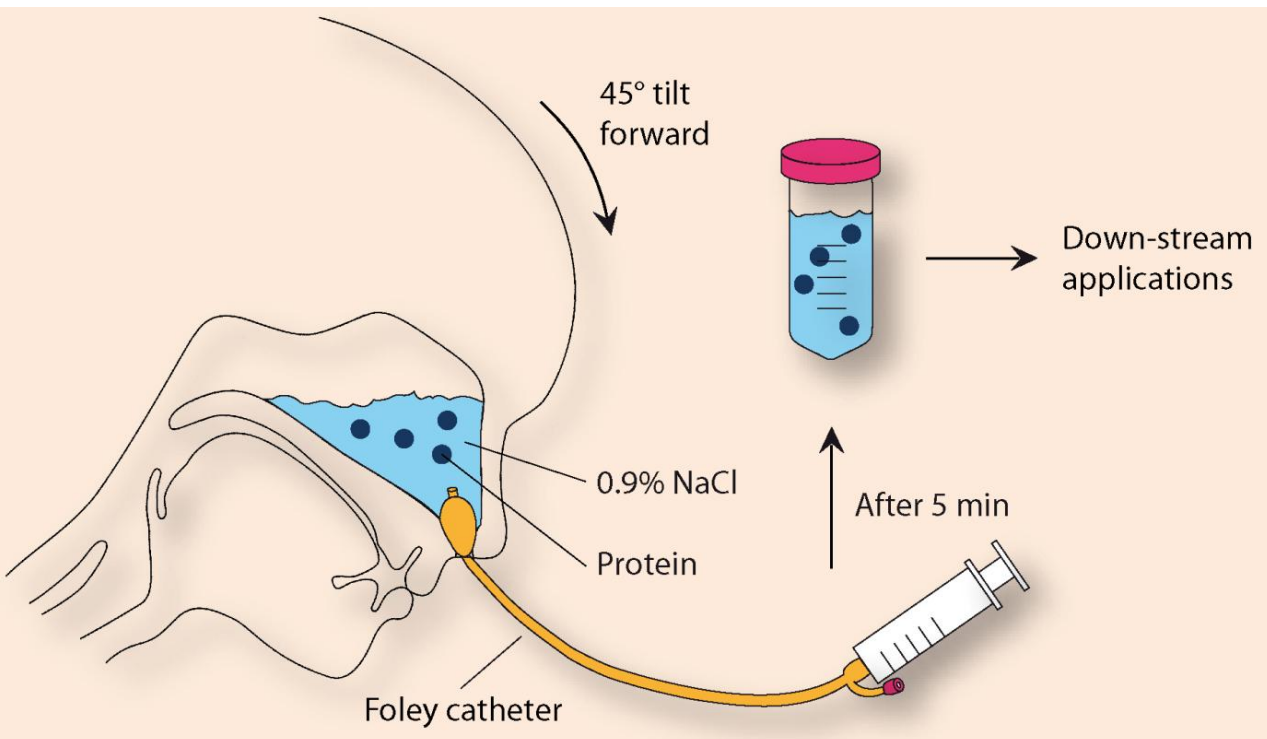

\section{Figure 4}

A schematic view of how nasal lavage fluid is sampled using a Foley catheter. Room tempered $0.9 \%$ saline solution is instilled into the nasal cavity where it remains during 5 minutes before it is retrieved back through the catheter and used for down-stream applications.

\section{GEL ELECTROPHORESIS}

\section{ONE-DIMENSIONAL GEL ELECTROPHORESIS}

Gel electrophoresis is one of the primary methods for protein analysis and onedimensional gel electrophoresis is a suitable choice if separation of a protein sample according to size is warranted. Different types of gels are available, whereof sodium dodecyl sulphate (SDS) polyacrylamide gel is very widespread. Polyacrylamide is particular suitable for electrophoresis, because it can withstand high voltage, be utilize for many downstream applications, transparent, etc. Prior to a gel run, the proteins are denaturized and made negatively charged to ensure size separation. Commonly the proteins are boiled with a reducing agent to reinforce the denaturizing effect of SDS and break as many tertiary structures as possible. The gel is made of a polyacrylamide matrix that contains SDS to keep a negatively charged and denaturizing environment for the proteins. Depending on concentrations of acrylamide and cross linkers, the pore size can be adjusted to suit the protein sample. Normally, the gel consists of two 
layers. First the stacking gel that concentrates the sample prior to migration into the second resolving gel where the proteins are separated. The negatively charged proteins in the sample are migrated in the gel through an electric field from the cathode to the anode, with help of a surrounding buffer. Large proteins have more difficult to migrate than small proteins, which thereby generate the final size generated pattern of the gel. The gel can be used for subsequent analyses, such as, western blot or staining [182183].

\section{TWO-DIMENSIONAL GEL ELECTROPHORESIS}

The development of two-dimensional gel electrophoresis (2-DE) is often associated with the birth of proteomics, which is the classical approach to analysis of differentially-expressed proteins. This is a powerful technique that enables the separation of many thousands of proteins for their subsequent identification and quantitative comparison [184]. The method is divided into a first and second dimension. In the first dimension, proteins are separated according to charge or isoelectric point with isoelectric focusing (IEF) and each protein moves until it reaches a point where the net charge is zero. The second dimension separates proteins according to molecular weight in sodium dodecyl sulfate-polyacrylamide gel electrophoresis (SDS-PAGE) [16]. The principle of 2-DE PAGE is seen in Figure 5. Normally, proteins do not share the same charge and molecular weight, leading to unique positions for each protein and its isoforms. Each protein becomes a spot on a gel and all proteins in a sample generate a pattern that can be considered unique for that sample. Two such patterns, or maps, from different samples can be compared in order to identify proteins of relevance to that particular state. In the beginning, native isoelectric focusing was used in the first dimension, but since 2-DE appeared as highly irreproducible both within and between laboratories, further development was necessary. The technique became more widespread with the introduction of immobilized $\mathrm{pH}$ gradients (IPGs) that standardized the first dimension and thereby allowed more accurate sample comparison and better reproducibility [185].

The 2-DE procedure enables characterization of up and down-regulated proteins, expression of new proteins and post-translational modifications of proteins at high resolution [186]. 2-DE is especially useful in analysis of post-translational modifications including phosphorylation and glycosylation. However, low abundance proteins, too high or too low molecular weight proteins and sometimes limited detection of highly hydrophobic proteins (for example membrane proteins) are shortcomings of 2-DE [187]. In order to enhance vision of low-abundant proteins, prefractioning to remove abundant proteins can be used or a more narrow $\mathrm{pH}$ gradient in the first dimension. It is more difficult to detect proteins outside of the molecular weight range. One way to override the problem is by adjusting the pore size of the gel, 
thereby setting new limits to which proteins pass through the gel, although this usually compromise separation of the other proteins.

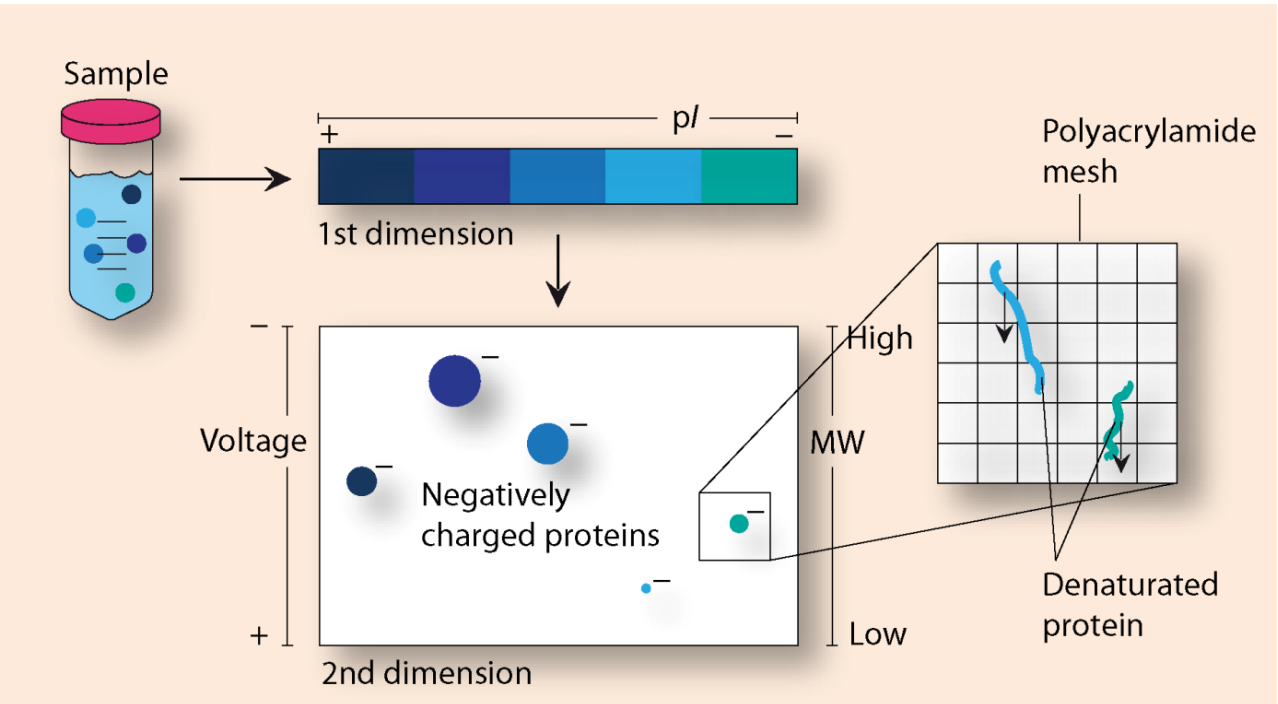

\section{Figure 5}

The principle of 2-DE PAGE. A sample with denaturized proteins is subjected to a first dimension where the proteins are separated according to isoelectric point followed by separation according to size. The proteins migrate through a mesh of polyacrylamide and move at different speed depending on size of the protein.

The most recent development in 2-DE is difference gel electrophoresis (DIGE). In this approach three fluorescent cyanine dyes are used to label the proteins before separation in the gels. Each dye and its protein sample, (control, case and internal standard) are pooled and separated simultaneously. This approach decreases the number of gels, as well as gel to gel variability, which is one of the drawbacks of the classical approach [15]. But since 2-DE is the oldest proteomic technique, all its advantages and disadvantages are well-known therefore making it possible to prioritize the problems and make them count as little as possible.

\section{FIRST DIMENSION}

In the first dimension, proteins are separated according to net charge by isoelectric focusing. However, prior sample preparation is vital. Sample preparation tends to minimize the differences between proteins in a sample so that the only lasting properties to separate the proteins from each other, in both first and second dimension, are net charge and molecular weight, respectively. This step secures the reproducibility 
of the analysis. The sample is normally solubilized, disaggregated, denaturized and reduced to secure the downstream application.

Proteins comprise various amino acids and their side chains in a unique composition. The net charge is the sum of all amino acids and side chains included in a protein and, depending on $\mathrm{pH}$ value, the protein can be positively or negatively charged. At a specific $\mathrm{pH}$, the net charge is zero for a protein, the isoelectric point $(\mathrm{p} I)$ of the proteins. In isoelectric focusing, proteins are added to an immobilized $\mathrm{pH}$ gradient that comprises a polyacrylamide gel with acidic and basic buffering groups. When the sample is subjected to an electric field it causes the protein to migrate towards either the anode or cathode until the net charge is zero and it reaches its specific $\mathrm{p} I$ position [188].

\section{SECOND DIMENSION}

Before starting the second dimension, the sample needs to be equilibrated under denaturized conditions. The purpose of the equilibration solution is to maintain the proteins denaturized and form a negatively-charged complex of SDS and protein. The coating of SDS on the proteins guarantees that they become mobile in the second dimension due to its negative charge. To reduce the denaturized proteins, prevent oxidation and cross-bridging of cysteins, DTT and iodoacetamide are added to the protein sample. Migration would be affected if these modifications were not made as they aim at retaining the properties similar between all proteins. SDS-PAGE separates according to molecular weight. The gel contains SDS to maintain a negatively-charged environment for the proteins. The pore size of the gel can be adjusted thanks to a cross linker that reacts chemically with the co-polymerized acrylamide monomers. The negatively-charged proteins in the sample from the first dimension are migrated in an electric field from the cathode to the anode. Large proteins have more difficulty in migrating than small proteins, which thereby generates the final pattern of the second dimension [188-189].

\section{VISUALIZATION AND IMAGE ANALYSIS}

There are several staining methods to choose between when the second dimension is completed. Depending on technique: all proteins on a gel, only post-translational modifications or defined proteins can be stained. Staining techniques that stain all proteins on a gel are most common. Examples of staining techniques include various fluorescent stains, radioactive isotope labeling, anionic dyes and silver staining. The type of method chosen depends on requirements in regard to sensitivity, linearity, reproducibility, compatibility with downstream applications (such as mass spectrometry), cost efficiency and type of proteins to be stained. Unfortunately, no method fulfills all requirements. An ideal stain would bind in a linear fashion and be 
able to detect very low protein amounts as proteins in biological sample may vary by six or more orders of magnitude [190].

Of the anionic dyes, Coomassie blue is one of the most common. The staining procedure is regressive, meaning the gel is first saturated with the dye solution followed by destaining, which is a process that takes advantage of the higher affinity of the dye for the proteins over the acrylamide gel. The dye binds by electrostatic interactions to basic and aromatic amino acids on the proteins. It is one of the least sensitive staining methods with a detection limit of around 100ng. Moreover, regressive staining makes batch-to-batch reproducibility difficult [191]. On the other hand, the method is cheap and user-friendly and suitable for downstream applications.

Silver staining is the most sensitive staining method and can detect proteins down to $0.1 \mathrm{ng}$ [192]. The method requires precise timing and is executed in several steps with different chemicals. In general the procedure is divided into four steps, where the first step is the fixation of the proteins in the gel in order to avoid diffusion of proteins and elute excessive and non-wanted substances from the gel that could interfere with the chemical staining procedure. This is followed by sensitization, which is used in the process to enhance the result by its binding to proteins and further reaction or binding with the silver ions. The next step is silver impregnation. Here the silver ions in silver nitrate are reduced to metallic silver under acidic conditions. Finally, the gel is developed by formaldehyde, carbonate and thiosulfate until the desired image level is obtained. The major drawback of silver staining is its rather limited dynamic range, mainly because high abundance proteins become saturated. This means that differences in amounts between proteins sometimes are underestimated [193]. Its major advantage is its high level of sensitivity, making it possible to detect low abundance proteins and the property of binding to negative groups, which makes it suitable for detection of glycoproteins.

In order to analyze the stained gels for differences in proteins expression, acquisition of a computerized image is performed. Most often, images are captured by a charged couple device (CCD) camera, laser densitometry or phosphor imagery. When the image is digitized it is divided into pixels, or tiny squares, that differ in signal intensity by varying the height of the pixel. Each protein spot consists of several pixels with varying height. In other words, darker protein spots generate higher pixels leading to higher optical density (OD) compared to fainter spots that generate the opposite. OD generates a numerical value, which can be used for comparison between protein profiles of groups included in statistical analysis. There are different software programs available on the market for gel image analysis. One of the major software programs is the PDQuest system, offered by Bio-Rad Laboratories, which is one of the most accurate and well-tried software packages. Once the image is digitized at least three basic steps are executed in the computer-assisted analysis of 2-DE gels. The first 
step is protein spot detection, followed by spot quantization and finally gel to gel matching of spot patterns [194]. At the beginning of the analysis it is also common that the software program distinguishes between accurate spots from artefacts such as streaking, air bubbles and noise. Further actions include normalization of the images that aim at reducing the risk of inaccurate result due to variation in spot intensities because of overall variation in protein amounts between gels and staining intensities. The image is also adjusted for warping, so that different gel images can be compared on similar terms. Finally statistical analysis is performed from the information generated.

\section{PROTEIN IDENTIFICATION BY MASS SPECTROMETRY}

Mass spectrometry revolutionized the field of proteomics and includes soft ionization techniques such as matrix-assisted laser desorption ionization (MALDI) and electrospray ionization (ESI). The techniques made it possible to identify proteins and perform large scale analysis of entire proteomes and the two techniques were thereby Nobel Prize awarded in chemistry 2002 [195-196]. In general, a mass spectrometer consists of an ionization source, a mass analyzer and an ion detector. Depending on combinations and optimizations of the three units, various platforms can be made [197].

\section{PEPTIDE MASS FINGERPRINTING}

Prior to a mass spectrometric analysis, the protein sample is digested with enzymes or chemicals in order to obtain peptide fragments. The most common enzyme is trypsin, which cleaves the protein at the C-terminal part of the amino acids lysine and arginine. Each protein gives rise to a unique protein fragmentation, due to the distinctive amino acid sequence in a protein. In a mass spectrometer, the fragments are ionized and fly towards a detector. The time of flight and mass of each fragment generates a mass to charge ratio, a peptide mass, which is compared to theoretical masses in a database. The more peptide fragments of a protein that is analyzed, the better and more accurate identification of a protein [197]. This method is possible since the mass spectrometers of today are so sensitive and accurate that the acquired masses can be compared to the theoretical masses derived mathematically from genome and protein databases [183].

\section{MALDI-TOF MASS SPECTROMETRY}

Matrix-assisted laser desorption ionization time-of-flight (MALDI-TOF) mass spectrometry is a sensitive technique that is used for protein identification via detection of peptides. The peptides are moved from a solid phase into gas phase. First, 
the peptide sample is mixed with a crystalline matrix of organic acid molecules. It is common with $\alpha$-cyano-4-hydroxy cinnamic acid and 2,5-dihydroxybenzoic acid as matrix for peptides. In the mass spectrometer, the sample is hit by a laser, so the matrix absorbs the energy, ultimately leading to evaporation and ionization of the now singly charged peptides. Subsequently, an electric field makes the peptides travel in a vacuum towards a detector. Light ions travels faster than heavy ions due to different mass to charge ratios and this can be used for identification [183]. A schematic view of a MALDI-TOF mass spectrometer is seen in Figure 6.

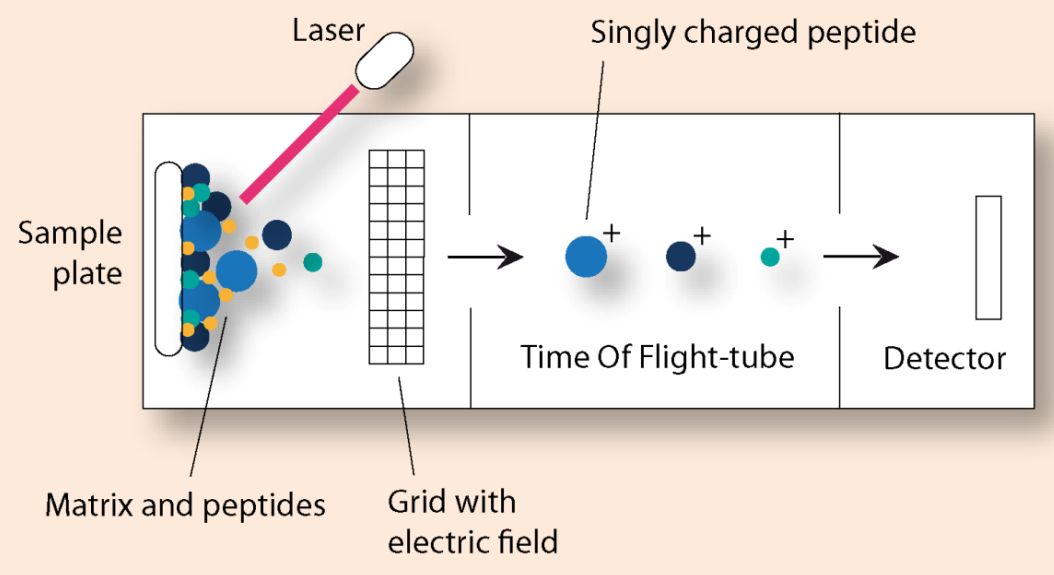

\section{Figure 6}

Schematic view of MALDI-TOF mass spectrometer for protein identification. The peptides are crystallized with an acidic matrix on a sample plate before laser pulses releases the charged peptides into an electric field. Lighter peptides travel faster towards the detector compared to heavier peptides.

\section{ELECTROSPRAY MASS SPECTROMETRY}

Electrospray ionization (ESI) is often used for tandem mass spectrometry (MS/MS) that determines peptide sequences of selected peptides by fragmentation. The sample, consisting of digested peptides, are transferred through a metal coated capillary and sprayed into a high electric field in atmospheric pressure. Small charged droplets are formed that travel towards the mass spectrometer that holds a lower potential. Before entering the vacuum of the mass analyzer, the droplets are subjected to a dry gas that makes the droplets evaporate and the charged peptides move into the analyzer. It is 
common with a quadrupole mass analyzer. Here the peptide ions are trapped between four charged metal rods and ejected on basis of each peptide's mass to charge ratio for detection. Several quadrupoles can be set in a row to analyze either proteins or peptides. For example, the first quadrupole capture all the peptide ions in a sample and ejects one peptide ion of choice into the second quadrupole where it is further fragmented by a gas into smaller peptides and amino acids. In the last quadrupole, the peptide ion fragments are analyzed, see Figure 7. This set-up makes it possible to sequence the peptide according to its amino acid sequence, either manually or by a automatic software. In general, ESI generates high sequence coverage and may also preserve protein structures, such as posttranslational modifications. On the other hand, analyses in ESI is much more time consuming than MALDI-TOF [183].

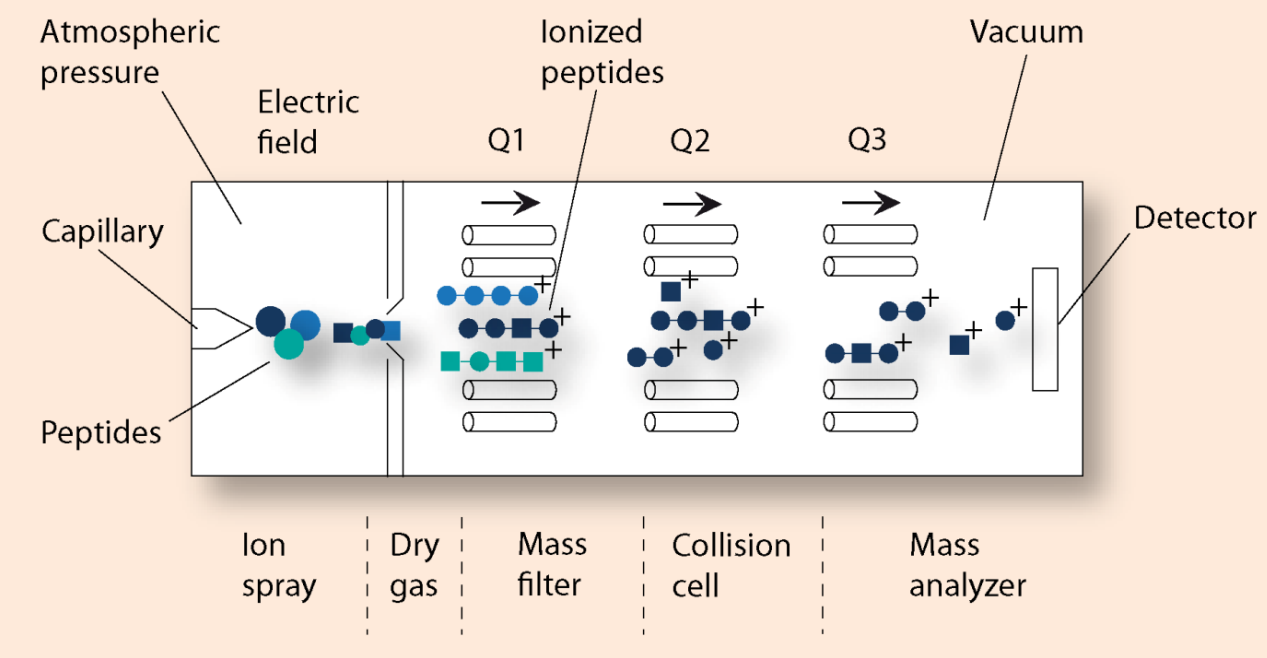

\section{Figure 7}

Schematic view of electrospray ionization using a triple quadrupole for peptide sequencing. A peptide sample is sprayed through a capillary and subsequently becomes charged. lons are selected by varying the voltage of the charged metal rods. In Q1 the peptide selected for analysis move into Q2 where the peptide is fragmented and last analyzed in Q3.

\section{WESTERN BLOTTING}

One- and two dimensional gel electrophoresis and mass spectrometry are valuable technologies to identify and quantify proteins. However, often the significant or important proteins found in a study are confirmed by a second, independent method, 
such as western blotting. Western blotting is furthermore used for immunodetection and quantitation of chosen proteins [198]. Blotting is in principle, transfer of large molecules on to a surface of an immobilizing membrane and can be executed in many ways. In this thesis, electrophoretic transfer of proteins from polyacrylamide gels to polyvinylidenedifluoride (PVDF) membranes has been used. A gel with proteins is placed on a PVDF membrane and is after assembly subjected to a current in a buffer solution, making the negatively charged proteins travel towards the positive anode out of the gel and onto the blotting membrane. The membrane is blocked for non-specific binding and then subjected to binding of a primary antibody. The primary antibody binds to its precise protein target on the membrane and to visualize its position on the membrane a secondary tagged antibody binds to the primary. The secondary antibody is tagged with for example horseradish peroxidase that can be visualized with chemiluminescence and captured by charged coupled device (CCD) camera. The digitized image can be further analyzed in software programs.

\section{STATISTICAL ANALYSES}

\section{UNIVARIATE ANALYSES}

Statistical analyses of results obtained from gel electrophoresis were performed with the non-parametric Mann-Whitney U test. Mann-Whitney compares the distribution between two unmatched groups and is suitable when the analyzed data is not Gaussian distributed. Correlations between groups were analyzed using nonparametric Spearman's rank correlation and Chi square test was used to compare two groups for demographic characteristics. In all statistical analyses, the significance level was set to $<0.05$.

\section{MULTIVARIATE ANALYSES}

Multivariate statistics was used as a complement to the univariate methods. Multivariate statistics is useful for group comparison when large amounts of data are to be analyzed. Contrary to traditional univariate statistical methods, which assume variable independence, multivariate statistics by advanced principal component analysis (PCA) and partial least squares (PLS) regressions, is capable of handling intercorrelated variables that is likely in biological systems. Moreover, by multivariate statistics it is possible to handle low subject-to-variables ratios and reduce the number of false positives without loss of statistical power [199]. 


\section{RESULTS AND DISCUSSION}

\section{PAPER I}

RSV is a widespread virus that infects millions of people each year [109]. Knowledge on the inflammatory protein response during RSV infection still remains to be elucidated. Hence, it was interesting to study the presence of SPLUNC1 and other innate immunity proteins in nasopharyngeal aspirate associated with RSV infection. Aspirates from small children admitted routinely to hospital because of suspected RSV infection was analyzed using a proteomic approach with 2-DE PAGE and mass spectrometry, in order to identify proteins in nasopharyngeal aspirate. Seven 2-DE gels were run, of which three samples with RSV and four samples without RSV. All gels showed a consistent protein pattern, and one of the gels was used for protein identification. Focus for protein identification was on low molecular weight proteins, and not on abundantly-occurring proteins, such as albumin or immunoglobulins. After the protein mapping we could identify 35 different gel spots corresponding to 15 unique proteins. Not surprisingly, many of the proteins belong to the innate immune system. Of these, SPLUNC1, mammaglobin B, Club (Clara) cell secretory protein 10 (CC10, CC16, uteroglobin), S100 calcium-binding proteins (S100A7, S100A7-like 2, S100A8, S100A9 and S100A16), cystatin 9-like 2, group 10 secretory phospholipase $\mathrm{A}_{2}$, lysozyme and several isoforms of lipocalin-1 were identified. Four of the proteins; S100A7-like 2, S100A16, group 10 secretory phospholipase $A_{2}$ and cystatin 9-like 2 have not been identified in nasal secretion earlier.

S100 protein belongs to a family of low molecular weight proteins with the same ability to bind calcium at two sites on the protein. This large family has both intracellular and extracellular functions and is often present as hetero and homodimers [133]. Of the 15 proteins identified in the nasopharyngeal aspirate, 5 belong to the S100 proteins; S100A7 (psoriasin), S100A7-like 2, S100A8 (calgranulin A, MRP-8), S100A9 (calgranulin B, MRP 14) and S100A16. Protein S100A8 and S100A9 have been found in nasal secretion before and they are often found as homodimers expressed in large quantities by neutrophils at inflammatory sites. They have been 
found in high levels during both viral and bacterial infections. During bacterial invasion, upon LPS release, S100A8 and S100A9 act as ligands to Toll-like receptor 4 and enhance LPS-induced inflammatory response [136]. Protein S100A7 is primarily present in kerationcytes in the epidermis and is often over-expressed in epidermal inflammatory states. For example during infection, S100A7 protects LPS-induced mitochondrial dysfunction in $\mathrm{HaCaT}$ cells and promotes secretion of IL-6 and IL-8 [200]. S100 proteins, especially S100A7, S100A8 and S100A9, have been shown to be important in nasal mucosal chronic rhinosinusitis, where a decrease of these proteins might lead to increased vulnerability to viral and bacterial infection [201]. Regarding protein S100A7-like 2 and S100A16, much is still unknown. However, S100A7-like 2 and S100A7 are structurally similar, implying comparable functions for the two proteins [202].

Group $\mathrm{X}$ phospholipase $\mathrm{A}_{2}$ is expressed at high levels in nasal mucosal cells, and this study has for the first time identified the protein in nasal secretion [203]. Phospholipase $\mathrm{A}_{2}$ is an enzyme that hydrolyses phospholipids into lysophospholipids and free fatty acids [204]. By this reaction, the protein is part of various biological processes, including host defense (by degradation of bacterial membranes), signal transduction and production of lipid mediators such as eicosanoids that are important in inflammation. Lysophospholipids has been shown to be part of the defense against enveloped viruses such as influenza virus [205]. RSV is also enveloped and presence of phospholipase $\mathrm{A}_{2}$ in nasopharyngeal aspirates may therefore be important to combat any ongoing viral infection.

The host defense protein, SPLUNC1 was identified in nasopharyngeal aspirates, of which seven isoforms were found. Beyond the native SPLUNC1 at $25 \mathrm{kDa}$, we also found a new smaller or truncated version of SPLUNC1 at $15 \mathrm{kDa}$. The $15 \mathrm{kDa}$ form was shown on 2-DE PAGE as two isoforms at $\mathrm{p} I 5.3$ and 5.4 and further verified using mass spectrometry. These $\mathrm{p} I \mathrm{~s}$ were similarly compared to the seven identified isoforms of $25 \mathrm{kDa}$ SPLUNC1, which have $\mathrm{p} / \mathrm{s}$ at 4.5-5.5. Normally a protein becomes truncated by elimination of the $\mathrm{C}$ - or $\mathrm{N}$-terminal part of the protein by mutation, premature termination of the transcription or by proteolytic post-translational modification. Furthermore, the protein can be shortened due to other reasons such as inappropriate sample handling. RSV is not known to endorse any proteolytic activity, compared to the common influenza virus and the truncated version was present both in samples with and without RSV implying that RSV is not the origin of the truncation [206].

In order to test how sample handling could influence the proteins of the upper respiratory tract, a newly-taken nasal lavage fluid sample was subjected to various conditions, such as repeated freeze/thaw cycles, prolonged stay in room temperature or dried in SpeedVac before freezing, all in order to try to induce fragmentation of the 
protein. However, none of the conditions tested were able to generate a truncated form of SPLUNC1. The truncated SPLUNC1 version was found in $50 \%$ of the nasopharyngeal aspirates analyzed. Interestingly, none of our previous studies of nasal lavage fluid or nasopharyngeal aspirates taken from healthy adults as control in this study displayed the $15 \mathrm{kDa}$ version [145-146, 207]. However, we found truncated SPLUNC1 in nasopharyngeal aspirates from elderly individuals admitted to hospital for suspected influenza diagnosis, although much less frequently (data not shown). The result implies that the truncation is not related to a genetic factor or the young age of the patients in the current study.

A potential candidate protease responsible for the truncation of SPLUNC1 is elastase. This protein is expressed abundantly by neutrophils at inflammatory sites, and increased levels of elastase have earlier been found in infants with RSV bronchiolitis [208]. Regardless, no correlation with neutrophil elastase activity and $25 \mathrm{kDa}$ and 15 kDa SPLUNC1 was seen. One study of SPLUNC1 in saliva also displays a shorter version of SPLUNC1 at $17 \mathrm{kDa}$. The authors state that it is a common breakdown product of full length SPLUNC1 often observed with both native and recombinant human SPLUNC1, but how the shorter product is generated remains unknown [209]. After collaboration with Professor Paul McCray and his research group at the University of Iowa we received material from primary bronchial airway epithelial cells. The cells express large amounts of native SPLUNC, but also a truncated $17 \mathrm{kDa}$ variant. Yet, the identified $17 \mathrm{kDa}$ SPLUNC1 was found to have a higher $\mathrm{p} I, 6.2$ compared to the $15 \mathrm{kDa}, 5.3$ found in nasopharynx, implicating that it is not the same truncated version. Some type of spontaneous or protease-induced cleavage of SPLUNC1 is probable, even though the exact mechanism is not identified.

While the precise function of SPLUNC1 is not known, the protein is believed to be a part of the innate immune system. SPLUNC1 was early shown to bind LPS and studies that followed showed SPLUNC1's ability to decrease the growth of several Gramnegative bacteria, such as Mycoplasma pneumoniae, Pseudomonas aeruginosa and Klebsiella pneumoniae [155-156, 158-160]. A later study indicated that other types of lipids active in innate immunity, instead of LPS, were the true assigned target for SPLUNC1 [157]. Nevertheless, the extent of the truncation of SPLUNC1 in nasopharyngeal aspirate, about one third of the protein, should have a substantial impact on both the function and structure of the protein. Consequently it may be hypothesized that the truncated version might lead to a greater susceptibility to infection due to reduced protective function against Gram-negative bacteria. The literature has shown that male gender is one risk factor for RSV and lower respiratory tract infection [112].

This is also supported by data from Linköping University Hospital for the period 2007-2009. In the surrounding population of 0-12 months of age, the incidence of boys 
seeking hospital care was double that of girls. $0.47 \%$ of the boys and $0.26 \%$ of the girls attended the hospital with diagnosed RSV infection ( $\mathrm{p}<0.01$, Pearson $\chi$ test). Of the boys $0.28 \%$ were hospitalized compared to $0.17 \%$ of the girls $(\mathrm{p}=0.06)$. These numbers conform to earlier knowledge on the overrepresentation of boys. Shorter and narrower airways and stronger eosinophils response among boys are thought to cause the higher risk for severe RSV infection [113]. Our results show significantly lower amounts of $25 \mathrm{kDa}$ SPLUNC1 among boys positive for RSV as compared to boys negative for RSV $(1.2 \pm 0.8$ versus 9.8 \pm 6.1 OD (mean \pm SEM, $\mathrm{p}<0.05)$ ). Also, while boys negative for RSV and girls negative and positive for RSV showed a correlation between native and truncated SPLUNC1 expression, boys' positive for RSV did not. In summary, the results indicate that the lower levels of native SPLUNC1 could be one mechanism behind the increased risk of RSV in boys.

In the children routinely admitted to hospital, their RSV infection is usually of a more severe nature and has sometimes spread to the lower respiratory tract. The protein profile may therefore be somewhat different compared to children with more mild RSV symptoms who never seek hospital care. Nevertheless, not all children included in the study are positive for RSV and it is thought that other infections, either viral or bacterial, are the probable cause of their symptoms. In addition, the children positive for RSV may have a bacterial co-infection. More studies should concentrate on studying whether children with or without a RSV infection also suffer from a bacterial infection in the lower respiratory tract, and if there is a correlation between these subjects and the $25 \mathrm{kDa}$ and $15 \mathrm{kDa}$ SPLUNC1. Such an approach might provide more insight into potential modulation of inflammatory responses during RSV infection related to SPLUNC1. 


\section{PAPER II}

The upper respiratory tract is in constant contact with the surrounding environment and thus very exposed to airborne compounds. Early effects induced by these compounds are reflected in the nasal mucosa. One environment containing irritating compounds is swimming pool facilities where respiratory symptoms have been widely documented over the years [39]. One likely cause of the problems is exposure to trichloramine, a disinfection by-product that is formed when chlorine comes in contact with nitrogen-containing compounds generated from bathers in the swimming pool water, which has an irritant effect on mucosal membranes. Trichloramine is very volatile and is released from the swimming pool into the surrounding air upon formation. Depending on conditions, such as $\mathrm{pH}$, chlorine concentration and ventilation, levels of trichloramine may vary in the air of swimming pool facilities [43].

We examined the occurrence of airway symptoms among 146 full-time employees working at 46 swimming pool facilities. A broad range of mucosal symptoms were displayed such as dry and mucous cough, hoarse throat, nasal obstruction rhinitis, headache, dryness and irritation of the eyes. A considerable portion of the employees $(17 \%)$ stated that they experienced airway problems related to work. Similar numbers have been shown in another study [41]. Trichloramine was measured in 9 facilities and showed air levels ranging from 0.04 to $0.36 \mathrm{mg} / \mathrm{m}^{3}$ and were on average $0.20 \mathrm{mg} / \mathrm{m}^{3}$. Sweden has not yet imposed a trichloramine guideline value. However, Héry et al proposed an airborne trichloramine level of $0.5 \mathrm{mg} / \mathrm{m}^{3}$ which was later adopted and recommended in WHO's guidelines [39, 54]. Thus, our measured trichloramine levels are all within the recommended levels. However, it has been suggested that susceptible subjects, such as atopic subjects and employees frequently exposed such as lifeguards and trainers, may experience airway symptoms in lower levels of trichloramine also. Parrat et al has proposed $0.3 \mathrm{mg} / \mathrm{m}^{3}$ as occupational exposure limit after demonstrating an increasing risk of irritative symptoms at levels of $0.2-0.3 \mathrm{mg} / \mathrm{m}^{3}$ [43]. This suggests that the levels found in Swedish swimming pools facilities are sufficient to generate mucosal symptoms.

Of the 146 full-time employees participating in this study, the health survey showed an average prevalence of $17 \%$ airway symptoms related to work. Interestingly, there was a large variation in airway symptoms experienced between facilities, and the majority of the personnel experiencing airway symptoms worked in a few of the facilities. Consequently, based on these initial results, 9 facilities were chosen for a more detailed investigation as five of them showed high prevalence of airway symptoms $(65 \%)$ and four facilities showed low prevalence of airway symptoms $(0 \%)$. The 
investigation included trichloramine measurements, nasal lavage sampling and nitric oxide in exhaled breath. Unexpectedly, airway symptoms and measured trichloramine values did not correlate despite the prevalence of airway symptoms experienced related to work in five of them. It is therefore difficult to point to trichloramine as the single cause of mucosal problems, even though many studies do show its irritative effects. In contrast to our results, one study shows that trichloramine levels in the air are directly correlated to health symptoms experienced and levels above $0.5 \mathrm{mg} / \mathrm{m}^{3}$ were shown to generate more irritative symptoms [210].

One study has shown stronger inflammatory response, by elevated release of IL-6 and IL-8, in alveolar epithelial lung cells exposed to swimming pool air compared to trichloramine alone [63]. This implies that there are other irritative compounds present, for example endotoxins derived from microorganisms, which are were measured but which may exert an impact on the health of personnel or visitors at swimming pool facilities. In addition to trichloramine, other factors in the swimming pool environment may influence the perceived air quality and also alter levels of disinfection by-products in the air. Adventure baths are thought to generate higher levels of trichloramine compared to regular swimming pools due to higher levels of turbulence in the water that would generate greater release of compounds [211]. In agreement with this we showed the highest mean trichloramine levels in two adventure baths and the peak values $\left(0.35-0.57 \mathrm{mg} / \mathrm{m}^{3}\right)$ were measured in the same facilities. Also, other factors, such as microbial growth, which is favored by the damp pool environment, can lead to the release of bacterial products, in turn generating an inflammatory response and causing airway symptoms [42]. It would be interesting to measure additional compounds such as trihalomethanes, and to study why airway problems are not consistent with trichloramine concentration in the nine swimming pool facilities participating in this study.

After a proteomic approach, with 2-DE and mass spectrometric analyses, we found significant protein alteration among subjects working at indoor swimming pool facilities compared to controls. Swimming pool personnel had more alpha-1antitrypsin and lactoferrin and less protein S100A8 and the difference in protein levels were most substantial between controls and the personnel who reported airway symptoms. Lactoferrin is a protein with many functions, whereof binding to free iron is the most evident, and thereby depriving the bacteria of its nutrients and delaying its colonization. Apart of exerting a reducing effect on viral and fungal growth, lactoferrin binds to LPS of Gram-negative bacteria walls that eventually results in lysis of the bacterium. During inflammation and infection, the local $\mathrm{pH}$ value drops due to high metabolic rate. Interestingly lactoferrin is still active, in contrast to many other proteins, which indicates an important role in innate immunity [212-213]. Increased 
levels have previously been found in patients with asthma and cystic fibrosis [213214].

Alpha-1-antitrypsin belongs to the family of serpins, a family consisting only of protease inhibitors. Alpha-1-antitrypsin is also an acute phase protein and show elevated levels in many inflammatory and post-infectious states, where it protects airway tissue by inhibiting neutrophil-derived elastase. In addition, alpha-1-antitrypsin demonstrates anti-inflammatory properties by affecting several cell types and modulating inflammatory responses by, for example, altering chemotaxis of neutrophils by binding IL-8. The protein is highly glycosylated and expressed as several isoforms. The glycosylation of the protein has been shown to be important in various disease states and glycosylation levels can often be elevated during inflammatory processes [215]. This is in agreement with our findings since we found elevated levels of the most glycosylated isoform, indicating an ongoing inflammatory process among swimming pool personnel with airway symptoms. Similar results have been shown in nasal lavage fluid among smokers and patients with allergic rhinitis [145-146].

Finally, protein S100A8 was found to be decreased among swimming pool personnel. This is a protein found in extracellular fluids at inflammatory sites as a heterodimer together with S100A9 and especially abundantly in neutrophils. It exerts antimicrobial activity by acting as a ligand to Toll-like receptor 4 upon bacterial invasion and production of LPS-induced production of cytokines [135]. In earlier publications, we have demonstrated how, in the upper airways, the endotoxin-binding protein SPLUNC1 may be a possible biomarker for environmentally-induced airway irritation [145-146, 155]. Consequently SPLUNC1 and nitric oxide, a marker of inflammation in exhaled breath, were measured. Neither the levels of SPLUNC1 or nitric oxide were altered. However, in this study we show a negative correlation between SPLUNC1 in nasal lavage fluid and exhaled nitric oxide.

Swimming pool facilities are clearly an environment that may generate airway symptoms among employees. Our results indicate that, in addition to trichloramine, other factors may be significant for the airway symptoms experienced. Future studies should focus on elucidating the importance of other factors such as the presence of endotoxins or mold spores in the facilities, and identifying whether proteins are chlorinated and if that may affect their functions. Also, protein biomarkers in nasal lavage fluid can be used to monitor upper airway inflammation and to understand the mechanisms involved. 


\section{PAPER III}

Occupational problems in relation to the metal industry and its use of MWF are a wellknown problem world-wide. Different problems arise depending on the type of MWF used, oil-based or water-based. In general, respiratory problems are connected to water-based MWF and skin problems to oil-based MWF [64]. In this study we investigated the association between exposure to water-based MWF and health status among personnel working at a larger industry in the southeast region of Sweden. The company had a history of skin problems among the workers and had therefore exchanged its oil-based MWF for water-based MWF. After this complaints about skin problems declined, but instead reports about airway irritation increased. Initially, a questionnaire was sent out to all personnel and 295 workers responded (78\% of total). Of these, 271 workers shared the same work space, a large hall where 102 operated machines that used MWF and the remaining 169 workers did not. 24 subjects worked in a separate assembly hall where no MWF were used. Among reported symptoms, mucous symptoms dominated including cough, hoarse and dry throat, irritated, stuffy or runny nose and itch, burn and irritation of eyes. Workers operating machines containing MWF showed the highest frequency of mucosal problems. Remarkably, workers not working with machines containing MWF also reported high levels of airway irritation. For example, nasal irritation in relation to work was found in $37 \%$ of the workers directly exposed to MWF, compared to $21 \%$ among the subjects working in the same hall indirectly exposed to MWF, but only in $8 \%$ of the subjects working in a separate assembly hall.

These results indicate that MWF have a pronounced effect on the work environment. Similarly, other studies have shown a high prevalence of airway irritation among workers exposed to MWF and especially high among workers handling synthetic fluids compared to straight oils [71-72]. The higher frequency of airway irritation among workers operating machines using MWF was not associated with worse psychosocial working conditions. For example, 50-55\% of those exposed to MWF reported that they had a stimulating work situation as compared to $29 \%$ of workers not exposed to MWF. Our survey also indicated that skin problems related to work were not associated with working with synthetic MWF; a prevalence of about $10 \%$ in each group.

At the same time as the company introduced water-based MWF, they had oil mist separators installed to improve the air quality. However, these separators only removed oil mist mechanically without preventing aerosols and gases from spreading to the air. In addition, the air was recycled back into the machine hall. After 
reconstruction work, the air from both oil mist separators and regular ventilation were redirected out of the building.

Among other occupational measurements, formaldehyde was measured before and after the reconstruction work and showed that the levels declined from $0.04 \mathrm{mg} / \mathrm{m}^{3}$ to $0.02 \mathrm{mg} / \mathrm{m}^{3}$. Most importantly, the effect of the reconstruction work was also observed among the workers who now reported less airway problems. The effect was most pronounced among workers indirectly exposed to MWF. Six months after the reconstruction work, all personnel exposed to MWF showed lower prevalence of airway symptoms, which had declined from $43 \%$ to $21 \%$. When comparing personnel exposed directly to MWF, $48 \%$ reported almost daily discomfort from the airways before and $30 \%$ after the reconstruction work. Among workers exposed indirectly, the levels had reduced from $39 \%$ to $13 \%$ for airway symptoms experienced daily. The fact that a considerable proportion of the workers directly exposed to MWF still experienced upper respiratory problems, however, implies the need for additional improvements in the machine hall. Examples of further preventive measures could be the reduction of the use of compressed air for cleaning, and enclosure of machines to minimize spread of metalworking aerosols.

Our study is one of the first of its kind in which protein alteration in the nasal mucosa due to exposure to MWF has been studied in humans. Lee et al have previously studied protein changes in bronchoalveolar lavage fluid from rats exposed to oil mist and found several proteins to be altered, proteins such as immunoglobulins, surfactantassociated proteins and protein $\mathrm{S} 100 \mathrm{~A} 8$, which is very much in line with the findings of this study [216]. We analyzed nasal lavage in 15 workers exposed to MWF. At the same time, 15 healthy, non-exposed controls were recruited for similar sampling. After proteomic analysis of the nasal lavage fluid, the protein patterns revealed five nasal proteins, all part of the immune system, to be significantly different between subjects with airway symptoms and subjects without airway symptoms. Protein S100A9 was increased among the subjects with airway symptoms and SPLUNC1, cystatin SN, IgJ and $\beta 2$-microglobulin were reduced. Protein S100A9 and SPLUNC1 are both part of the mucosal innate immune system and have shown to be active in defense against microbes, for example, by either induced chemotaxis of neutrophils or by preventing growth of bacteria, respectively [158, 217]. Protein S100A9 is often found as a heterodimer together with protein S100A8 and it may be hypothesized that these two proteins should be found at comparable levels [133]. In Paper II, S100A8 was decreased while S100A9 was unaltered among the swimming pool personnel also displaying airway symptoms connected to work. In this study, S100A9 was significantly increased while the levels of S100A8 were not significantly changed. This implies that an irritative environment may generate inflammation of the nasal mucosa with a distorted balance between the two proteins. Also, cystatin SN is a part 
of the innate immune system where it protects the mucosal tissue against excessive injury [218]. IgJ and $\beta 2$-microglobulin are both part of the adaptive immune system since they are essential for the formation of $\operatorname{IgM}$ and $\operatorname{IgA}$, respectively [130, 219]. Secretory $\operatorname{IgA}$ and secretory $\operatorname{IgM}$ are important components of the mucosal immune defense and represent the early activation of the adaptive immune system [220].

Our study confirms the presence of airway symptoms related to work among subjects exposed to MWF. This is shown even though the levels of MWF-generated substances were low and is associated with altered levels of airway immune proteins. We also showed how preventive measures in the form of reconstruction work can exert beneficial effects on the health of workers exposed to the fluid. Future studies should focus on how airway inflammation is connected to particular MWF compounds and further elucidate on the role of the above-mentioned proteins as potential biomarkers. 
Buildings suffering from excessive dampness are susceptible to microbial growth or chemical degradation of structural material. Both outcomes may result in the release of compounds into the surrounding air, which can cause non-specific symptoms among individuals with prolonged stay in these damp, moldy buildings. Symptoms are referred to as sick-building syndrome and include fatigue, headache, irritation and itching of the eyes, as well as throat and nasal problems [94]. This study was initiated after reports of health effects related to damp damage at two different workplaces and aimed at identifying effects on the upper airway mucosa due to spending time in these buildings by studying protein changes in nasal lavage fluid.

At each of the two buildings enrolled in the study, simultaneous indoor environmental investigations were performed together with a standardized work environment questionnaire regarding indoor climate, perceived work-related symptoms and work situation [171]. Workplace A included 22 subjects (51\% response frequency) who answered the questionnaire, while workplace B included 15 subjects ( $71 \%$ response frequency). Both workplaces showed notable occurrence of symptoms in relation to work environment. Workplace A reported higher prevalence of work-related upper airway symptoms (23-27\%), compared to workplace B (7-13\%). The opposite result was observed regarding ocular symptoms, where workplace B (27\%) reported a higher frequency than A (18\%). It is worth mentioning here that reported symptoms are 2-5 times higher than the reference group. About one fifth experienced general symptoms, such as headache and fatigue at both workplaces, while skin problems were low at both (4-13\%). The variation in symptoms experienced between the two indicates a difference in the type of exposure at these workplaces.

After the initial questionnaire, one group from each workplace was subjected to nasal lavage sampling and a second questionnaire was administered concerning daily, perceived symptoms in relation to work environment. Additionally, a healthy control group of 13 subjects was recruited. 14 subjects from workplace A and 15 subjects from workplace B were included and the prevalence of health problems showed comparable results as the initial questionnaire. After proteomic analysis and subsequent univariate statistical analysis, several proteins were shown to be significantly different between workplace A and B compared to controls. Interestingly, few of the significant proteins were the same in both workplaces, again suggesting a difference in the type of exposure between the two groups. Consequently, a multivariate data analysis was performed to investigate potential group variation. In univariate statistics, false positive results can be a problem when the study material consists of smaller groups that generate large amounts of data. Multivariate statistics 
reduce this risk and are also capable of managing intercorrelated variables, which are probably present in biological systems [199].

20 proteins were found significant for the group separation. Different proteins were found to be unique for each of the three groups. For example, protein S100A8 was a determinant for the protein pattern in subjects from workplace A and lysozyme for workplace B. These specific expression patterns perhaps reflect the difference between the environments studied, where workplace A had a more damp profile with microbial growth, while workplace B had an environment with release of volatile organic compounds due to water leakage and faulty mixture of the adhesive under the flooring. Thus, the different types of exposures may induce a distinct immune reaction with accompanying protein alterations leading to the group separations observable by using multivariate statistics. This is strengthened by the results from the initial questionnaire, which showed more upper airway problems in workplace A and more ocular symptoms in workplace B. At the same time it is important to stress that these results should be verified in more and larger-scale studies. Nevertheless, the results from analyzing nasal lavage fluid using proteomics and multivariate statistics are promising in order to develop an objective tool providing biomarkers for the sometimes vague mucosal symptoms linked to damp, moldy buildings.

Two potential biomarkers, SPLUNC1 and alpha-1-antitrypsin, found in the previous studies (Papers I-III) were also studied in nasal lavage fluid from the personnel working in damp buildings and 2-DE PAGE and western blot analysis showed that SPLUNC1 was decreased in nasal lavage fluid from workplace A and alpha-1antitrypsin was increased in nasal lavage fluid from workplace B. This corresponds to earlier findings where SPLUNC1 is decreased and alpha-1-antirypsin increased in smokers [146] as well as in swimming pool personnel as seen in Paper II. Due to the ability of SPLUNC1 to regulate the sodium balance in the airway mucosa, lower expression levels might indicate impaired hydration [166]. With less hydration of the mucosa, microbes and particles are more easily trapped because of impaired cilia movement. The importance of SPLUNC1 for airway hydration, together with its direct antimicrobial activity, suggests that lower levels of SPLUNC1 lead to deteriorated clearance of microbes and dust $[143,160]$. Alpha-1-antitrypsin is normally present at inflammatory sites where it protects tissue against injury, especially by inhibition of neutrophil-derived elastase. This protein is also known to be highly glycosylated and present as several isoforms that can be altered during various inflammatory states [215]. Alpha-1-antitrypsin has a theoretical molecular weight of $47 \mathrm{kDa}$, but the increased isoforms we found had a higher molecular mass of $59 \mathrm{kDa}$, which probably is explained by glycosylation.

In addition to SPLUNC1, two important proteins, S100A8 and S100A9, were found to be significantly increased in personnel from workplace A compared to controls. 
Moreover, S100A8 was a significant component of workplace A-related nasal lavage fluid protein profile in the multivariate analysis. The two proteins are often found as a heterodimer and possess antimicrobial properties by depriving microorganisms of zinc, which is an essential nutrient. The heterodimer acts as a danger-associated molecular pattern (DAMP) molecule and stimulates innate immunity cells that results in the amplification of the proinflammatory response [133]. Higher levels of S100A8 and S100A9 among personnel at workplace A, but not at workplace B, are therefore consistent with the presence of microorganisms in workplace A.

Our study demonstrates how protein profiles in nasal lavage fluid can be used to observe how work in damp, moldy buildings affects the upper airway mucosa and further shows that the profile may change when the dampness is associated with the presence of microorganisms. We also show that the mucosal symptoms experienced among personnel are objectively manifested at protein level by alterations in innate immunity proteins. Future studies should aim at expanding the study and including additional buildings in order to perform further environmental investigations, with a more extensive number of samples. In particular, to evaluate the multivariate model and the usefulness of nasal lavage fluid biomarker signatures when investigating building-related illness at different workplaces, biomonitoring after reconstruction measures and for prediction of disease progression. 


\section{CONCLUDING REMARKS AND FUTURE PERSPECTIVES}

My thesis focuses on upper airway mucosal inflammation and how the mucosa is affected by exposure to irritative and microbial agents. This has been studied by using a proteomic approach, with a gel-based system and mass spectrometry, for analyses of nasal lavage fluid in order to identify proteins and discover protein alterations. In addition, by studying factors on site through environmental investigations, health questionnaires and additional biological analyses we have tried to understand the background to these protein alterations and their impact on health.

We have shown how environments, such as swimming pool facilities, metal industries that use MWF and damp, moldy buildings (Papers II-IV), give rise to high prevalence of mucosal symptoms among the personnel in these settings. The subjects displayed symptoms ranging from cough, rhinitis and phlegm to headaches and fatigue. This was found despite the relatively low levels of airborne irritants as shown by the environmental examinations. It is, from our results, difficult to point out one single cause as responsible for the symptoms manifested. For example, in Paper II we found no co-variation between trichloramine levels and the prevalence of airway symptoms in the swimming pool facilities. In this case it is likely that indoor swimming pools just like MWF and damp buildings facilitate microbial growth and formation of proinflammatory compounds like endotoxins and beta-glucans, which might contribute to the airway problems. Thus, most workplaces contain more than one possible source of irritant exposure. Like in the metal industry where MWF generate a complex environment that apart from oil mist and formaldehyde could give rise to other aldehydes, amines and particles of varying size that may be harmful. The same is true for damp buildings with Sick-Building Syndrome in which many different volatile organic compounds can be detected although it has been difficult to pin-point one causative agent. Consequently, it is not unlikely that the presence of several different irritants and microbial agents, although in low concentrations, altogether generates a "cocktail effect" that causes airway mucosal inflammation.

This thesis illustrates the potential of a proteomic approach in the search for new biomarkers for identifying irritation of the upper respiratory tract at an early stage and preventing the occurrence of more severe symptoms such as asthma. Rhinitis has been 
shown to be a potent risk factor for developing asthma and repeated exposure of a sensitizing agent may lead to progression of the disease. Studies with people suffering from severe asthma have shown that those who also had rhinitis reported a more severe disease [221]. Furthermore, occupational exposure to e.g. reactive chemicals is a well-known risk factor for developing occupational asthma. The traditional view is that asthma arises from workplace exposure to airway sensitizing agents in a previously non-sensitized person. However, it is becoming more evident that occupational asthma can be caused by long-term and low-level exposure generated from a wide range of causative irritative agents [222]. This shows the important role that early upper airway biomarkers might serve to be able to prevent a progression of the inflammation to the lungs.

A wide range of proteins were identified in the nasal lining fluid, such as albumin, lysozyme C, immunoglobulins, cystatins, lactoferrin, mammaglobins, S100-proteins, lipocalins, protease inhibitors and SPLUNC1. Notably, the common aspect of Papers I-IV is the presence and alterations of innate immunity proteins in nasal lavage fluid. This illustrates the importance of a functioning mucosal defense against microbes and how this can be affected in response to an irritative challenge. Interestingly, some of the innate immunity proteins were highlighted in several of the studies; SPLUNC1, alpha-1-antitrypsin, protein S100A8 and S100A9, is presented in Table 1. Both S100A8 and S100A9 are abundantly found in neutrophils and can be released upon activation at inflammatory sites. This might explain increased levels found in nasal lavage fluid from metalworkers (Paper III) and individuals working in damp buildings (Paper IV). However, we could not find more myeloperoxidase (MPO) or elastase, typical neutrophil markers, in these individuals. It is also important to point out that considerable amounts of S100A8 and S100A9 are always found in nasal lavage fluid also in healthy individuals without inflammation. Notably, lower levels of S100A8 were found in the subjects working in swimming pool facilities (Paper II). The reason for this opposite effect compared to Paper III and IV is not known. Since increased levels of S100A8 and S100A9 in Paper IV were only found in the subjects working in a building with a moldy profile it is possible to speculate that microbes besides being an important aspect of the damp building also was important in the exposure to MWF but not in the swimming pool environment. Moreover, the roles of S100A8 and S100A9, together or separately, in inflammation are not fully elucidated and both proinflammatory and anti-inflammatory functions have been suggested [136, 223]. Another possible inflammatory biomarker found in our studies is alpha-1-antitrypsin, which was increased in the subjects studied in Paper II and IV. This is in line with a previous study of smokers [146] and with alpha-1-antitrypsin being an acute phase protein. Interestingly, glycosylation of the protein appeared to be a sensitive sign of airway symptoms. Finally, lower levels of SPLUNC1 were found in Paper I, III and IV. Together with previous studies $[145,224]$ this strongly suggests that decreased 
expression of SPLUNC1, which may be due to an adverse effect of the exposure on SPLUNC1 producing cells, is a key feature in airway irritation. Considering the suggested anti-microbial function of SPLUNC1 (see Figure 3) this implicates a weakened microbial defense in subjects exposed to irritating agents. In line, there is some support in the literature for this notion [225]. Recently, a new role of SPLUNC1 as regulator of sodium balance has been suggested. This makes it possible to speculate that decreased level of SPLUNC1 entails an impaired mucosal hydration that could lead to both an enhanced vulnerability to irritating agents and to an increased inflammation.

Summary of the protein changes in nasal lavage fluid from subjects with upper airway symptoms in Paper I-IV.

\section{Table 1}

\begin{tabular}{lcccc}
\hline & Paper I & Paper II & Paper III & Paper IV \\
\cline { 2 - 5 } & RSV & $\begin{array}{c}\text { Indoor swimming } \\
\text { pool }\end{array}$ & MWF & Damp buildings \\
\hline SPLUNC1 & $\downarrow$ & - & $\downarrow$ & $\downarrow$ \\
S100A8 & - & $\downarrow$ & - & $\uparrow$ \\
S100A9 & - & - & $\uparrow$ & $\uparrow$ \\
Alpha-1- & - & $\uparrow$ & - & $\uparrow$ \\
antitrypsin & & & & \\
\hline
\end{tabular}

As shown in Table 1, some proteins were found changed in more than one exposure setting. This indicates, not surprisingly, that they could be general markers of an upper airway irritative inflammation instead of reflecting a specific exposure. At the same time, proteomics of nasal lavage fluid produces an array of protein data from the airways that altogether probably can be used to extract more information than just identifying significant protein alterations one by one. In Paper IV, multivariate statistics were used for group comparison and interestingly different protein profiles were found in nasal lavage fluid from the two workplaces studied, of which one was associated with a moldy environment while the other was associated with a more chemical exposure. This illustrates the potential for the future to use proteomics in combination with multivariate statistics for biomarker discovery. A major advantage is the ability to scan large amounts of proteins in a single analysis. But also because in 
biosystems, like the airways, several parameters, i.e. proteins, have coordinate expressions making multivariate statistics models more reliable and informative compared to univariate statistics where a single parameter at a time is used.

Future studies should focus on more detailed analysis of the four innate immune proteins found in this work. As shown by the 2-DE analysis, these proteins are expressed as different isoforms most likely caused by posttranslational modifications. But the molecular differences and their functional roles are largely unknown. It would therefore be interesting to further characterize SPLUNC1 isoforms and to investigate if the truncated variant has an impaired or altered functional role in the upper respiratory tract. Likewise, it would be of interest to study the role of S100A8 and S100A9 isoforms in mucosal defense and elucidate if altered levels of these proteins are reflected in the formation of the heterodimer. Finally, our results suggest enrichment of glycosylated alpha-1-antitrypsin in nasal lavage fluid as a biomarker and more studies to understand the importance of the glycosylation is warranted.

Combined, the papers presented in this thesis have generated a number of potential biomarkers for irritation of the upper respiratory mucosa at an early stage. However, to be of clinical use, these proposed proteins must be studied in larger groups of exposed individuals and the time and cost of measuring them must be reduced. This could be achieved by higher-throughput methods, such as ELISA, bead array-based analyses or designated quantitative mass spectrometry techniques. Such methods applied to larger groups would serve to verify the findings of this thesis. Furthermore, multivariate statistics should be used to identify and evaluate groups of markers specific to ongoing inflammation of the nasal mucosa that even might be specific to each particular exposure. Finally, it is clear that subjects suffer from upper airway symptoms despite low levels of irritative agents measured. Therefore, it is important in further studies to make the exposure assessments as complete as possible and include these data in the multivariate biological models to elucidate the etiology of the airway symptoms. 


\section{ACKNOWLEDGEMENTS}

Many people have contributed to the work in this thesis and I would like to express my genuine gratitude to everyone who has helped and supported me during my years as PhD student.

I would like to especially thank:

Mats Lindahl, my supervisor, who first kindled my interest in proteomics and taking me on as a PhD student. Thank you for always keeping your door open and your expertise in the field of proteomics and respiratory problems.

Bijar Ghafouri, my co-supervisor, for all the hours' spent and outstanding expertise in the lab, as well as all funny pranks and teaching me more about Kurdish traditions.

Pål Graff, my co-supervisor, for all your help over the years and all the answers to my questions about occupational medicine. So far, by looking at you I can see myself in ten years.

All co-authors without whom this thesis would have been difficult to complete: Christer Tagesson, Ulf Flodin, Erik Kihlström, Thomas Schön, Britt Åkerlind and Kjell Ydreborg.

Stefan Ljunggren for being an excellent friend and accompany me as a fellow $\mathrm{PhD}$ student. Patrik Olausson for your friendship and all the laughs over the years. Karin Wåhlén for being my newfound friend and also helping out during my husband's disputation. Liam Ward for being an excellent office mate and English glossary, all in one. Anders Carlsson for enlightening us of your småländska heritage and all the fun times at the lab. Niclas Stensson for nice times at work and contributing to the growing group of $\mathrm{PhD}$ students. Inger Nordén Larsson for always being so helpful and creating an enjoyable atmosphere. Helen Karlsson for your contagious energy and stand-in as laboratory supervisor when necessary. Reza Nosratabadi, Per Leanderson and Jan Andersson for nice times at the lab and around the fika-table. Johanna Lönn for lighten up the lab from time to time. 
All my colleagues at Occupational and Environmental Medicine for always being so nice and friendly over the years and making the clinic a pleasant place to work at. Particularly I like to thank Bengt Ståhlbom and Lotta Gustafsson for help in various matters. I also like to thank Marie Malander, at the Department of Clinical and Experimental Medicine, for valuable help in connection with my disputation.

All my friends and family for making time outside of work so valuable and worth longing for.

Danne, my love and best friend, for endless support and encouragement. 


\section{REFERENCES}

1. Ross MH, Kaye GI, \& Pawlina W (2003) Histology: a text and atlas (Lippincott Williams and Wilkins) 4th Ed.

2. Alberts B, Johnson A, Lewis J, et al. (2002) Molecular biology of the cell (Garland Science) 4th Ed.

3. Pilette C, Ouadrhiri Y, Godding V, et al. Lung mucosal immunity: immunoglobulin-A revisited. Eur Respir J 2001;18(3):571-588.

4. Anonymous. Biological markers in environmental health research. Committee on Biological Markers of the National Research Council. Environ Health Perspect 1987;74:3-9.

5. WHO. Environmental Health Criteria 237. Principles for evaluating health risks in children associated with exposure to chemicals. WHO 2006.

6. Behrens T, Bonberg N, Casjens S, et al. A practical guide to epidemiological practice and standards in the identification and validation of diagnostic markers using a bladder cancer example. Biochim Biophys Acta 2014;1844(1 Pt A):145-155.

7. Drabovich AP, Martinez-Morillo E, \& Diamandis EP. Toward an integrated pipeline for protein biomarker development. Biochim Biophys Acta 2014.

8. Dalle-Donne I, Rossi R, Colombo R, et al. Biomarkers of oxidative damage in human disease. Clin Chem 2006;52(4):601-623.

9. Madu CO \& Lu Y. Novel diagnostic biomarkers for prostate cancer. $J$ Cancer 2010;1:150-177.

10. Strimbu K \& Tavel JA. What are biomarkers? Curr Opin HIV AIDS 2010;5(6):463466.

11. Wilkins MR, Sanchez JC, Gooley AA, et al. Progress with proteome projects: Why all proteins expressed by a genome should be identified and how to do it. Biotechnol Genet Eng 1996;13:19-50.

12. Brower V. Proteomics: biology in the post-genomic era. Companies all over the world rush to lead the way in the new post-genomics race. EMBO Rep 2001;2(7):558-560.

13. Mann M \& Jensen ON. Proteomic analysis of post-translational modifications. Nat Biotechnol 2003;21(3):255-261.

14. Anderson NL \& Anderson NG. Proteome and proteomics: new technologies, new concepts, and new words. Electrophoresis 1998;19(11):1853-1861.

15. Frantzi M, Bhat A, \& Latosinska A. Clinical proteomic biomarkers: relevant issues on study design \& technical considerations in biomarker development. Clin Transl Med 2014;3(1):7.

16. O'Farrell PH. High resolution two-dimensional electrophoresis of proteins. $J$ Biol Chem 1975;250(10):4007-4021.

17. WHO (1999) Occupational Medicine in Europe: Scope and Competencies. in EUR/ICP/EHBI 0202 04, eds MacDonald E, Baranski B, \& Wilford J (World Health Organization, Bilhoven). 
18. Tan J \& Bernstein JA. Occupational asthma: an overview. Curr Allergy Asthma Rep 2014;14(5):431.

19. Edling C, Nordberg G, \& Nordberg M (2003) Arbets- och miljömedicin - en lärobok om hälsa och miljö (Studentlitteratur) 2nd Ed.

20. Johannessen A, Bakke PS, Hardie JA, et al. Association of exposure to environmental tobacco smoke in childhood with chronic obstructive pulmonary disease and respiratory symptoms in adults. Respirology 2012;17(3):499-505.

21. Melloni BB. Lung cancer in never-smokers: radon exposure and environmental tobacco smoke. Eur Respir J 2014;44(4):850-852.

22. Karlsson H, Lindbom J, Ghafouri B, et al. Wear particles from studded tires and granite pavement induce pro-inflammatory alterations in human monocyte-derived macrophages: a proteomic study. Chem Res Toxicol 2011;24(1):45-53.

23. Park EK, Takahashi K, Jiang Y, et al. Elimination of asbestos use and asbestos-related diseases: an unfinished story. Cancer Sci 2012;103(10):1751-1755.

24. Leung CC, Yu IT, \& Chen W. Silicosis. Lancet 2012;379(9830):2008-2018.

25. de Jong K, Boezen HM, Kromhout H, et al. Pesticides and other occupational exposures are associated with airway obstruction: the LifeLines cohort study. Occup Environ Med 2014;71(2):88-96.

26. Balmes JR. Occupational contribution to the burden of chronic obstructive pulmonary disease. J Occup Environ Med 2005;47(2):154-160.

27. Balmes J, Becklake M, Blanc P, et al. American Thoracic Society Statement: Occupational contribution to the burden of airway disease. Am J Respir Crit Care Med 2003;167(5):787-797.

28. Koh DH, Kim JI, Kim KH, et al. Welding fume exposure and chronic obstructive pulmonary disease in welders. Occup Med (Lond) 2014.

29. Park DU, Ryu SH, Kim SB, et al. An assessment of dust, endotoxin, and microorganism exposure during waste collection and sorting. J Air Waste Manag Assoc 2011;61(4):461-468.

30. Lacasse Y, Girard M, \& Cormier Y. Recent advances in hypersensitivity pneumonitis. Chest 2012;142(1):208-217.

31. Cormier Y. Hypersensitivity pneumonitis (extrinsic allergic alveolitis): A Canadian historical perspective. Can Respir J 2014;21(5):277-278.

32. Rimmer J \& Ruhno JW. 6: Rhinitis and asthma: united airway disease. Med J Aust 2006;185(10):565-571.

33. Moscato G, Vandenplas O, Gerth Van Wijk R, et al. Occupational rhinitis. Allergy 2008;63(8):969-980.

34. Shusterman D. Occupational irritant and allergic rhinitis. Curr Allergy Asthma Rep 2014;14(4):425.

35. Willart MA \& Lambrecht BN. The danger within: endogenous danger signals, atopy and asthma. Clin Exp Allergy 2009;39(1):12-19.

36. Siracusa A, Desrosiers M, \& Marabini A. Epidemiology of occupational rhinitis: prevalence, aetiology and determinants. Clin Exp Allergy 2000;30(11):1519-1534.

37. Castano R, Gautrin D, Theriault G, et al. Occupational rhinitis in workers investigated for occupational asthma. Thorax 2009;64(1):50-54.

38. Seed MJ, Carder M, Gittins M, et al. Do all occupational respiratory sensitisers follow the united airways disease model? Thorax 2009;64(7):642-643.

39. WHO. Guidelines for Safe Recreational Water Environments. World Health Organization 2006;2: Swimming Pools and Similar Environments:Available: http://www.who.int/water_sanitation_health/bathing/srwe2full.pdf [accessed 31 August 2011]. 
40. Fernandez-Luna A, Gallardo L, Plaza-Carmona M, et al. Respiratory function and changes in lung epithelium biomarkers after a short-training intervention in chlorinated vs. ozone indoor pools. PLoS One 2013;8(7):e68447.

41. Massin N, Bohadana $\mathrm{AB}$, Wild $\mathrm{P}$, et al. Respiratory symptoms and bronchial responsiveness in lifeguards exposed to nitrogen trichloride in indoor swimming pools. Occup Environ Med 1998;55(4):258-263.

42. Dang B, Chen L, Mueller C, et al. Ocular and respiratory symptoms among lifeguards at a hotel indoor waterpark resort. J Occup Environ Med 2010;52(2):207-213.

43. Parrat J, Donze G, Iseli C, et al. Assessment of occupational and public exposure to trichloramine in Swiss indoor swimming pools: a proposal for an occupational exposure limit. Ann Occup Hyg 2012;56(3):264-277.

44. Fantuzzi G, Righi E, Predieri G, et al. Prevalence of ocular, respiratory and cutaneous symptoms in indoor swimming pool workers and exposure to disinfection by-products (DBPs). Int J Environ Res Public Health 2010;7(4):1379-1391.

45. Thickett KM, McCoach JS, Gerber JM, et al. Occupational asthma caused by chloramines in indoor swimming-pool air. Eur Respir J 2002;19(5):827-832.

46. Jacobs JH, Spaan S, van Rooy GB, et al. Exposure to trichloramine and respiratory symptoms in indoor swimming pool workers. Eur Respir J 2007;29(4):690-698.

47. Nemery B, Hoet PH, \& Nowak D. Indoor swimming pools, water chlorination and respiratory health. Eur Respir J 2002;19(5):790-793.

48. Levesque B, Duchesne JF, Gingras S, et al. The determinants of prevalence of health complaints among young competitive swimmers. Int Arch Occup Environ Health 2006;80(1):32-39.

49. Bernard A, Nickmilder M, \& Voisin C. Outdoor swimming pools and the risks of asthma and allergies during adolescence. Eur Respir J 2008;32(4):979-988.

50. Bernard A, Carbonnelle S, Michel O, et al. Lung hyperpermeability and asthma prevalence in schoolchildren: unexpected associations with the attendance at indoor chlorinated swimming pools. Occup Environ Med 2003;60(6):385-394.

51. Bernard A, Carbonnelle S, Dumont X, et al. Infant swimming practice, pulmonary epithelium integrity, and the risk of allergic and respiratory diseases later in childhood. Pediatrics 2007;119(6):1095-1103.

52. Nystad W, Haberg SE, London SJ, et al. Baby swimming and respiratory health. Acta Paediatr 2008;97(5):657-662.

53. Font-Ribera L, Villanueva CM, Nieuwenhuijsen MJ, et al. Swimming pool attendance, asthma, allergies, and lung function in the Avon Longitudinal Study of Parents and Children cohort. Am J Respir Crit Care Med 2011;183(5):582-588.

54. Hery M, Hecht G, Gerber JM, et al. Exposure to chloramines in the atmosphere of indoor swimming pools. Ann Occup Hyg 1995;39(4):427-439.

55. Schmalz C, Frimmel FH, \& Zwiener C. Trichloramine in swimming pools--formation and mass transfer. Water Res 2011;45(8):2681-2690.

56. Soltermann F, Widler T, Canonica S, et al. Comparison of a novel extraction-based colorimetric (ABTS) method with membrane introduction mass spectrometry (MIMS): trichloramine dynamics in pool water. Water Res 2014;58:258-268.

57. Lian L, E Y, Li J, et al. Volatile disinfection byproducts resulting from chlorination of uric acid: implications for swimming pools. Environ Sci Technol 2014;48(6):32103217.

58. AFSSET. Evaulation des risques sanitaires liés aux piscine. Partie 1: piscines réglementées. Edition scientifique juin 2010. 
59. Carbonnelle S, Francaux M, Doyle I, et al. Changes in serum pneumoproteins caused by short-term exposures to nitrogen trichloride in indoor chlorinated swimming pools. Biomarkers 2002;7(6):464-478.

60. Font-Ribera L, Kogevinas M, Zock JP, et al. Short-term changes in respiratory biomarkers after swimming in a chlorinated pool. Environ Health Perspect 2010;118(11):1538-1544.

61. Romberg K, Bjermer L, \& Tufvesson E. Exercise but not mannitol provocation increases urinary Clara cell protein (CC16) in elite swimmers. Respir Med 2011;105(1):31-36.

62. Lagerkvist BJ, Bernard A, Blomberg A, et al. Pulmonary epithelial integrity in children: relationship to ambient ozone exposure and swimming pool attendance. Environ Health Perspect 2004;112(17):1768-1771.

63. Schmalz C, Wunderlich HG, Heinze R, et al. Application of an optimized system for the well-defined exposure of human lung cells to trichloramine and indoor pool air. $J$ Water Health 2011;9(3):586-596.

64. OSHA (1999) Metalworking Fluids: Safety and Health Best Practices Manual.

65. Gruvberger B, Isaksson M, Frick M, et al. Occupational dermatoses in a metalworking plant. Contact Dermatitis 2003;48(2):80-86.

66. Suuronen K, Henriks-Eckerman ML, Riala R, et al. Respiratory exposure to components of water-miscible metalworking fluids. Ann Occup Hyg 2008;52(7):607614.

67. de Groot A, Geier J, Flyvholm MA, et al. Formaldehyde-releasers: relationship to formaldehyde contact allergy. Part 2: Metalworking fluids and remainder. Contact Dermatitis 2010;63(3):129-139.

68. Colt JS, Friesen MC, Stewart PA, et al. A case-control study of occupational exposure to metalworking fluids and bladder cancer risk among men. Occup Environ Med 2014;71(10):667-674.

69. Zhao Y, Krishnadasan A, Kennedy N, et al. Estimated effects of solvents and mineral oils on cancer incidence and mortality in a cohort of aerospace workers. Am J Ind Med 2005;48(4):249-258.

70. Jarvholm B, Fast K, Lavenius B, et al. Exposure to cutting oils and its relation to skin tumors and premalignant skin lesions on the hands and forearms. Scand $J$ Work Environ Health 1985;11(5):365-369.

71. Lillienberg L, Burdorf A, Mathiasson L, et al. Exposure to metalworking fluid aerosols and determinants of exposure. Ann Occup Hyg 2008;52(7):597-605.

72. Greaves IA, Eisen EA, Smith TJ, et al. Respiratory health of automobile workers exposed to metal-working fluid aerosols: respiratory symptoms. Am J Ind Med 1997;32(5):450-459.

73. Bakerly ND, Moore VC, Vellore AD, et al. Fifteen-year trends in occupational asthma: data from the Shield surveillance scheme. Occup Med (Lond) 2008;58(3):169174.

74. Graff P, Elmsjo L, Bjorkander J, et al. Occupational rhinitis caused by tolyltriazole in metalworking fluids. Scand J Work Environ Health 2008;34(5):403-404.

75. Sollenberg J \& Ståhlbom B. Emission of morpholine from metalworking fluids. Occupational Hygiene 1998;4(3-6):281-288.

76. Chen MR, Tsai PJ, Chang CC, et al. Particle size distributions of oil mists in workplace atmospheres and their exposure concentrations to workers in a fastener manufacturing industry. J Hazard Mater 2007;146(1-2):393-398. 
77. Henriks-Eckerman ML, Suuronen K, Jolanki R, et al. Determination of occupational exposure to alkanolamines in metal-working fluids. Ann Occup Hyg 2007;51(2):153160.

78. Trafny EA. Microorganisms in metalworking fluids: Current issues in research and management. Int J Occup Med Environ Health 2013;26(1):4-15.

79. Veillette M, Thorne PS, Gordon T, et al. Six month tracking of microbial growth in a metalworking fluid after system cleaning and recharging. Ann Occup Hyg 2004;48(6):541-546.

80. Burton CM, Crook B, Scaife H, et al. Systematic review of respiratory outbreaks associated with exposure to water-based metalworking fluids. Ann Occup Hyg 2012;56(4):374-388.

81. Barber CM, Burton CM, Robinson E, et al. Hypersensitivity pneumonitis due to metalworking fluid exposures. Chest 2013;143(4):1189.

82. Bracker A, Storey E, Yang C, et al. An outbreak of hypersensitivity pneumonitis at a metalworking plant: a longitudinal assessment of intervention effectiveness. Appl Occup Environ Hyg 2003;18(2):96-108.

83. Park D. The occupational exposure limit for fluid aerosol generated in metalworking operations: limitations and recommendations. Saf Health Work 2012;3(1):1-10.

84. Lim $\mathrm{CH}$, Yu IJ, Kim HY, et al. Inflammatory and immunological responses to subchronic exposure to endotoxin-contaminated metalworking fluid aerosols in F344 rats. Environ Toxicol 2005;20(2):212-218.

85. Lima $\mathrm{CH}, \mathrm{Yu} \mathrm{IJ}, \mathrm{Kim} \mathrm{HY}$, et al. Effect of water-soluble metal working fluid aerosols on respiratory system after 13 weeks of repeated inhalation exposure in F344 rats. Toxicol Ind Health 2005;21(9):207-213.

86. Crook B \& Burton NC. Indoor moulds, Sick Building Syndrome and building related illness. Fungal Biology Reviews 2010;24(3-4):106-113.

87. Norback D, Wieslander G, Nordstrom K, et al. Asthma symptoms in relation to measured building dampness in upper concrete floor construction, and 2-ethyl-1hexanol in indoor air. Int J Tuberc Lung Dis 2000;4(11):1016-1025.

88. Viegi G, Simoni M, Scognamiglio A, et al. Indoor air pollution and airway disease. Int J Tuberc Lung Dis 2004;8(12):1401-1415.

89. Wieslander G, Norback D, Nordstrom K, et al. Nasal and ocular symptoms, tear film stability and biomarkers in nasal lavage, in relation to building-dampness and building design in hospitals. Int Arch Occup Environ Health 1999;72(7):451-461.

90. Jarnstrom H, Saarela K, Kalliokoski P, et al. Comparison of VOC and ammonia emissions from individual PVC materials, adhesives and from complete structures. Environ Int 2008;34(3):420-427.

91. Gminski R, Marutzky R, Kevekordes S, et al. Chemosensory irritations and pulmonary effects of acute exposure to emissions from oriented strand board. Hum Exp Toxicol 2011;30(9):1204-1221.

92. Ernstgard L, Lof A, Wieslander G, et al. Acute effects of some volatile organic compounds emitted from water-based paints. J Occup Environ Med 2007;49(8):880889.

93. Araki A, Kawai T, Eitaki Y, et al. Relationship between selected indoor volatile organic compounds, so-called microbial VOC, and the prevalence of mucous membrane symptoms in single family homes. Sci Total Environ 2010;408(10):22082215.

94. Norback D. An update on sick building syndrome. Curr Opin Allergy Clin Immunol 2009;9(1):55-59. 
95. Karvala K, Toskala E, Luukkonen R, et al. Prolonged exposure to damp and moldy workplaces and new-onset asthma. Int Arch Occup Environ Health 2011;84(7):713721.

96. Karvala K, Nordman H, Luukkonen R, et al. Asthma related to workplace dampness and impaired work ability. Int Arch Occup Environ Health 2014;87(1):1-11.

97. Norback D, Zock JP, Plana E, et al. Mould and dampness in dwelling places, and onset of asthma: the population-based cohort ECRHS. Occup Environ Med 2013;70(5):325-331.

98. Ruoppi PI, Husman TM, Reiman MH, et al. Nasal symptoms among residents in moldy housing. Scand J Work Environ Health 2003;29(6):461-467.

99. Crawford JO \& Bolas SM. Sick building syndrome, work factors and occupational stress. Scand J Work Environ Health 1996;22(4):243-250.

100. Runeson-Broberg R \& Norback D. Sick building syndrome (SBS) and sick house syndrome (SHS) in relation to psychosocial stress at work in the Swedish workforce. Int Arch Occup Environ Health 2013;86(8):915-922.

101. Brauer C \& Mikkelsen S. The influence of individual and contextual psychosocial work factors on the perception of the indoor environment at work: a multilevel analysis. Int Arch Occup Environ Health 2010;83(6):639-651.

102. Fiedler N, Kelly-McNeil K, Ohman-Strickland P, et al. Negative affect and chemical intolerance as risk factors for building-related symptoms: a controlled exposure study. Psychosom Med 2008;70(2):254-262.

103. Wieslander G, Norback D, \& Venge P. Changes of symptoms, tear film stability and eosinophilic cationic protein in nasal lavage fluid after re-exposure to a damp office building with a history of flooding. Indoor Air 2007;17(1):19-27.

104. Akpinar-Elci M, White SK, Siegel PD, et al. Markers of upper airway inflammation associated with microbial exposure and symptoms in occupants of a water-damaged building. Am J Ind Med 2013;56(5):522-530.

105. Purokivi MK, Hirvonen MR, Randell JT, et al. Changes in pro-inflammatory cytokines in association with exposure to moisture-damaged building microbes. Eur Respir J 2001;18(6):951-958.

106. Zhang X, Sahlberg B, Wieslander G, et al. Dampness and moulds in workplace buildings: associations with incidence and remission of sick building syndrome (SBS) and biomarkers of inflammation in a 10 year follow-up study. Sci Total Environ 2012;430:75-81.

107. Nair H, Nokes DJ, Gessner BD, et al. Global burden of acute lower respiratory infections due to respiratory syncytial virus in young children: a systematic review and meta-analysis. Lancet 2010;375(9725):1545-1555.

108. McNamara PS \& Smyth RL. The pathogenesis of respiratory syncytial virus disease in childhood. Br Med Bull 2002;61:13-28.

109. Lambert L, Sagfors AM, Openshaw PJ, et al. Immunity to RSV in Early-Life. Front Immunol 2014;5:466.

110. Thorburn K, Harigopal S, Reddy V, et al. High incidence of pulmonary bacterial coinfection in children with severe respiratory syncytial virus (RSV) bronchiolitis. Thorax 2006;61(7):611-615.

111. van Asten L, van den Wijngaard C, van Pelt W, et al. Mortality attributable to 9 common infections: significant effect of influenza A, respiratory syncytial virus, influenza B, norovirus, and parainfluenza in elderly persons. $J$ Infect Dis 2012;206(5):628-639.

112. Simoes EA. Environmental and demographic risk factors for respiratory syncytial virus lower respiratory tract disease. J Pediatr 2003;143(5 Suppl):S118-126. 
113. Nagayama Y, Tsubaki T, Nakayama S, et al. Gender analysis in acute bronchiolitis due to respiratory syncytial virus. Pediatr Allergy Immunol 2006;17(1):29-36.

114. Nagayama Y, Tsubaki T, Sawada K, et al. Age and sex as factors of response to RSV infections among those with previous history of wheezing. Pediatr Allergy Immunol 2006;17(5):376-381.

115. Cassimos DC, Tsalkidis A, Tripsianis GA, et al. Asthma, lung function and sensitization in school children with a history of bronchiolitis. Pediatr Int 2008;50(1):51-56.

116. Sigurs N, Aljassim F, Kjellman B, et al. Asthma and allergy patterns over 18 years after severe RSV bronchiolitis in the first year of life. Thorax 2010;65(12):1045-1052.

117. Thomsen SF, van der Sluis S, Stensballe LG, et al. Exploring the association between severe respiratory syncytial virus infection and asthma: a registry-based twin study. Am J Respir Crit Care Med 2009;179(12):1091-1097.

118. Janssen R, Bont L, Siezen CL, et al. Genetic susceptibility to respiratory syncytial virus bronchiolitis is predominantly associated with innate immune genes. J Infect Dis 2007;196(6):826-834.

119. Avadhanula V, Rodriguez CA, Devincenzo JP, et al. Respiratory viruses augment the adhesion of bacterial pathogens to respiratory epithelium in a viral species- and cell type-dependent manner. J Virol 2006;80(4):1629-1636.

120. McGillivary G, Mason KM, Jurcisek JA, et al. Respiratory syncytial virus-induced dysregulation of expression of a mucosal beta-defensin augments colonization of the upper airway by non-typeable Haemophilus influenzae. Cell Microbiol 2009;11(9):1399-1408.

121. Monick MM, Yarovinsky TO, Powers LS, et al. Respiratory syncytial virus upregulates TLR4 and sensitizes airway epithelial cells to endotoxin. J Biol Chem 2003;278(52):53035-53044.

122. Simoes EA. Respiratory syncytial virus infection. Lancet 1999;354(9181):847-852.

123. Boucherat O, Boczkowski J, Jeannotte L, et al. Cellular and molecular mechanisms of goblet cell metaplasia in the respiratory airways. Exp Lung Res 2013;39(4-5):207-216.

124. Widdicombe JH. Regulation of the depth and composition of airway surface liquid. $J$ Anat 2002;201(4):313-318.

125. Sigurdsson HH, Kirch J, \& Lehr CM. Mucus as a barrier to lipophilic drugs. Int J Pharm 2013;453(1):56-64.

126. Raphael GD, Jeney EV, Baraniuk JN, et al. Pathophysiology of rhinitis. Lactoferrin and lysozyme in nasal secretions. J Clin Invest 1989;84(5):1528-1535.

127. Packer NH, Lawson MA, Jardine DR, et al. Analyzing glycoproteins separated by two-dimensional gel electrophoresis. Electrophoresis 1998;19(6):981-988.

128. Fietta A, Bardoni A, Salvini R, et al. Analysis of bronchoalveolar lavage fluid proteome from systemic sclerosis patients with or without functional, clinical and radiological signs of lung fibrosis. Arthritis Res Ther 2006;8(6):R160.

129. Frutiger S, Hughes GJ, Paquet N, et al. Disulfide bond assignment in human J chain and its covalent pairing with immunoglobulin M. Biochemistry 1992;31(50):1264312647.

130. Rosano C, Zuccotti S, \& Bolognesi M. The three-dimensional structure of beta2 microglobulin: results from X-ray crystallography. Biochim Biophys Acta 2005;1753(1):85-91.

131. Archimandriti DT, Dalavanga YA, Cianti R, et al. Proteome analysis of bronchoalveolar lavage in individuals from Metsovo, nonoccupationally exposed to asbestos. J Proteome Res 2009;8(2):860-869. 
132. Yammani RR. S100 proteins in cartilage: role in arthritis. Biochim Biophys Acta 2012;1822(4):600-606.

133. Ehrchen JM, Sunderkotter C, Foell D, et al. The endogenous Toll-like receptor 4 agonist S100A8/S100A9 (calprotectin) as innate amplifier of infection, autoimmunity, and cancer. J Leukoc Biol 2009;86(3):557-566.

134. Foell D, Frosch M, Sorg C, et al. Phagocyte-specific calcium-binding S100 proteins as clinical laboratory markers of inflammation. Clin Chim Acta 2004;344(1-2):37-51.

135. Vogl T, Tenbrock K, Ludwig S, et al. Mrp8 and Mrp14 are endogenous activators of Toll-like receptor 4, promoting lethal, endotoxin-induced shock. Nat Med 2007;13(9):1042-1049.

136. Goyette $\mathrm{J} \&$ Geczy CL. Inflammation-associated S100 proteins: new mechanisms that regulate function. Amino Acids 2010.

137. Lindahl M, Stahlbom B, \& Tagesson C. Identification of a new potential airway irritation marker, palate lung nasal epithelial clone protein, in human nasal lavage fluid with two-dimensional electrophoresis and matrix-assisted laser desorption/ionization-time of flight. Electrophoresis 2001;22(9):1795-1800.

138. Bingle CD \& Bingle L. Characterisation of the human plunc gene, a gene product with an upper airways and nasopharyngeal restricted expression pattern. Biochim Biophys Acta 2000;1493(3):363-367.

139. Weston WM, LeClair EE, Trzyna W, et al. Differential display identification of plunc, a novel gene expressed in embryonic palate, nasal epithelium, and adult lung. $J$ Biol Chem 1999;274(19):13698-13703.

140. Bingle CD, Seal RL, \& Craven CJ. Systematic nomenclature for the PLUNC/PSP/BSP30/SMGB proteins as a subfamily of the BPI fold-containing superfamily. Biochem Soc Trans 2011;39(4):977-983.

141. Bingle CD, LeClair EE, Havard S, et al. Phylogenetic and evolutionary analysis of the PLUNC gene family. Protein Sci 2004;13(2):422-430.

142. Bingle CD \& Craven CJ. PLUNC: a novel family of candidate host defence proteins expressed in the upper airways and nasopharynx. Hum Mol Genet 2002;11(8):937943.

143. Di YP. Functional roles of SPLUNC1 in the innate immune response against Gramnegative bacteria. Biochem Soc Trans 2011;39(4):1051-1055.

144. Bartlett JA, Hicks BJ, Schlomann JM, et al. PLUNC is a secreted product of neutrophil granules. J Leukoc Biol 2008;83(5):1201-1206.

145. Ghafouri B, Irander K, Lindbom J, et al. Comparative proteomics of nasal fluid in seasonal allergic rhinitis. J Proteome Res 2006;5(2):330-338.

146. Ghafouri B, Stahlbom B, Tagesson C, et al. Newly identified proteins in human nasal lavage fluid from non-smokers and smokers using two-dimensional gel electrophoresis and peptide mass fingerprinting. Proteomics 2002;2(1):112-120.

147. Passali D, Sarafoleanu C, Manea C, et al. PLUNC proteins positivity in patients with chronic rhinosinusitis: a case-control study. ScientificWorldJournal 2014;2014:853583.

148. Tsou YA, Peng MT, Wu YF, et al. Decreased PLUNC expression in nasal polyps is associated with multibacterial colonization in chronic rhinosinusitis patients. Eur Arch Otorhinolaryngol 2014;271(2):299-304.

149. Di YP, Tkach AV, Yanamala N, et al. Dual Acute Pro-Inflammatory and Anti-Fibrotic Pulmonary Effects of SPLUNC1 After Exposure to Carbon Nanotubes. Am J Respir Cell Mol Biol 2013.

150. Thaikoottathil JV, Martin RJ, Di PY, et al. SPLUNC1 deficiency enhances airway eosinophilic inflammation in mice. Am J Respir Cell Mol Biol 2012;47(2):253-260. 
151. Britto CJ \& Cohn L. BPIFA1 (SPLUNC1) in Airway Host Protection and Respiratory Disease. Am J Respir Cell Mol Biol 2014.

152. Sentani K, Oue N, Sakamoto N, et al. Gene expression profiling with microarray and SAGE identifies PLUNC as a marker for hepatoid adenocarcinoma of the stomach. Mod Pathol 2008;21(4):464-475.

153. Cheng M, Chen Y, Yu X, et al. Diagnostic utility of LunX mRNA in peripheral blood and pleural fluid in patients with primary non-small cell lung cancer. BMC Cancer 2008;8:156.

154. Canny G \& Levy O. Bactericidal/permeability-increasing protein (BPI) and BPI homologs at mucosal sites. Trends Immunol 2008;29(11):541-547.

155. Ghafouri B, Kihlstrom E, Tagesson C, et al. PLUNC in human nasal lavage fluid: multiple isoforms that bind to lipopolysaccharide. Biochim Biophys Acta 2004;1699(12):57-63.

156. Zhou HD, Wu MH, Shi L, et al. [Effect of growth inhibition of the secretory protein SPLUNC1 on Pseudomonas aeruginosa]. Zhong Nan Da Xие Xие Bao Yi Xие Ban 2006;31(4):464-469.

157. Ning F, Wang C, Berry KZ, et al. Structural characterization of the pulmonary innate immune protein SPLUNC1 and identification of lipid ligands. FASEB $J$ 2014;28(12):5349-5360.

158. Lukinskiene L, Liu Y, Reynolds SD, et al. Antimicrobial activity of PLUNC protects against Pseudomonas aeruginosa infection. J Immunol 2011;187(1):382-390.

159. Liu Y, Bartlett JA, Di ME, et al. SPLUNC1/BPIFA1 contributes to pulmonary host defense against Klebsiella pneumoniae respiratory infection. Am $J$ Pathol 2013;182(5):1519-1531.

160. Chu HW, Thaikoottathil J, Rino JG, et al. Function and regulation of SPLUNC1 protein in Mycoplasma infection and allergic inflammation. $J$ Immunol 2007;179(6):3995-4002.

161. Gakhar L, Bartlett JA, Penterman J, et al. PLUNC is a novel airway surfactant protein with anti-biofilm activity. PLoS One 2010;5(2):e9098.

162. Zhou HD, Li XL, Li GY, et al. Effect of SPLUNC1 protein on the Pseudomonas aeruginosa and Epstein-Barr virus. Mol Cell Biochem 2008;309(1-2):191-197.

163. Garcia-Caballero A, Rasmussen JE, Gaillard E, et al. SPLUNC1 regulates airway surface liquid volume by protecting $\mathrm{ENaC}$ from proteolytic cleavage. Proc Natl Acad Sci U S A 2009;106(27):11412-11417.

164. Hobbs CA, Blanchard MG, Alijevic O, et al. Identification of the SPLUNC1 ENaCinhibitory domain yields novel strategies to treat sodium hyperabsorption in cystic fibrosis airway epithelial cultures. Am J Physiol Lung Cell Mol Physiol 2013;305(12):L990-L1001.

165. Rollins BM, Garcia-Caballero A, Stutts MJ, et al. SPLUNC1 expression reduces surface levels of the epithelial sodium channel $(\mathrm{ENaC})$ in Xenopus laevis oocytes. Channels (Austin) 2010;4(4):255-259.

166. Tarran R \& Redinbo MR. Mammalian short palate lung and nasal epithelial clone 1 (SPLUNC1) in pH-dependent airway hydration. Int J Biochem Cell Biol 2014;52:130135.

167. Bartlett J, Gakhar L, Penterman J, et al. PLUNC: a multifunctional surfactant of the airways. Biochem Soc Trans 2011;39(4):1012-1016.

168. Ahlbom A, Alfvén T, Alfredsson L, et al. (2006) Grunderna i epidemiologi (Studentlitteratur).

169. Levin KA. Study design III: Cross-sectional studies. Evid Based Dent 2006;7(1):2425 . 
170. Gertsman BB (1998) Epidemiology kept simple (Wiley-Liss).

171. Andersson K. Epidemiological Approach to Indoor Air Problems*. Indoor air 1998;8(S4):32-39.

172. Do TQ, Moshkani S, Castillo P, et al. Lipids including cholesteryl linoleate and cholesteryl arachidonate contribute to the inherent antibacterial activity of human nasal fluid. J Immunol 2008;181(6):4177-4187.

173. Hentschel J, Muller U, Doht F, et al. Influences of nasal lavage collection-, processing- and storage methods on inflammatory markers--evaluation of a method for non-invasive sampling of epithelial lining fluid in cystic fibrosis and other respiratory diseases. J Immunol Methods 2014;404:41-51.

174. Lindahl M, Stahlbom B, \& Tagesson C. Two-dimensional gel electrophoresis of nasal and bronchoalveolar lavage fluids after occupational exposure. Electrophoresis 1995;16(7):1199-1204.

175. Rabone SJ \& Saraswati SB. Acceptance and effects of nasal lavage in volunteer woodworkers. Occup Med (Lond) 1999;49(6):365-369.

176. Bakke JV, Wieslander G, Norback D, et al. Atopy, symptoms and indoor environmental perceptions, tear film stability, nasal patency and lavage biomarkers in university staff. Int Arch Occup Environ Health 2008;81(7):861-872.

177. Pitrez PM, Brennan S, Turner S, et al. Nasal wash as an alternative to bronchoalveolar lavage in detecting early pulmonary inflammation in children with cystic fibrosis. Respirology 2005;10(2):177-182.

178. Riechelmann H, Deutschle T, Friemel E, et al. Biological markers in nasal secretions. Eur Respir J 2003;21(4):600-605.

179. Norback D \& Wieslander G. Biomarkers and chemosensory irritations. Int Arch Occup Environ Health 2002;75(5):298-304.

180. Zhang YJ, Luroe S, Schieber F, et al. Immunoassay-based measurement of clinical biomarkers for monitoring changes in nasal cavity. $J$ Pharm Biomed Anal 2009;50(5):823-830.

181. Nikasinovic-Fournier L, Just J, Seta N, et al. Nasal lavage as a tool for the assessment of upper-airway inflammation in adults and children. $J$ Lab Clin Med 2002;139(3):173-180.

182. Schagger H \& von Jagow G. Tricine-sodium dodecyl sulfate-polyacrylamide gel electrophoresis for the separation of proteins in the range from 1 to $100 \mathrm{kDa}$. Anal Biochem 1987;166(2):368-379.

183. Westermeier R (2005) Electrophoresis in practice (Wiley-VCH) Fourth Ed.

184. Klose J. Protein mapping by combined isoelectric focusing and electrophoresis of mouse tissues. A novel approach to testing for induced point mutations in mammals. Humangenetik 1975;26(3):231-243.

185. Bjellqvist B, Ek K, Righetti PG, et al. Isoelectric focusing in immobilized $\mathrm{pH}$ gradients: principle, methodology and some applications. J Biochem Biophys Methods 1982;6(4):317-339.

186. Celis JE, Ostergaard M, Jensen NA, et al. Human and mouse proteomic databases: novel resources in the protein universe. FEBS Lett 1998;430(1-2):64-72.

187. Chevalier F. Highlights on the capacities of "Gel-based" proteomics. Proteome Sci 2010;8:23.

188. Rabilloud T \& Lelong C. Two-dimensional gel electrophoresis in proteomics: a tutorial. J Proteomics 2011;74(10):1829-1841.

189. Gorg A, Obermaier C, Boguth G, et al. The current state of two-dimensional electrophoresis with immobilized pH gradients. Electrophoresis 2000;21(6):10371053. 
190. Berth M, Moser FM, Kolbe M, et al. The state of the art in the analysis of twodimensional gel electrophoresis images. Appl Microbiol Biotechnol 2007;76(6):12231243.

191. Rabilloud T. Detecting proteins separated by 2-D gel electrophoresis. Anal Chem 2000;72(1):48A-55A.

192. Gorg A, Weiss W, \& Dunn MJ. Current two-dimensional electrophoresis technology for proteomics. Proteomics 2004;4(12):3665-3685.

193. Rabilloud T. Silver staining of 2D electrophoresis gels. Methods Mol Biol 2012;893:61-73.

194. Marengo E, Robotti E, Antonucci F, et al. Numerical approaches for quantitative analysis of two-dimensional maps: a review of commercial software and home-made systems. Proteomics 2005;5(3):654-666.

195. Tanaka A, Waki H, Ido Y, et al. Protein and polymer analyses up to m/z 100000 by laser ionization time-of-flight mass spectrometry. Rapid communications in mass spectrometry 1988;2(8):151-153.

196. Fenn JB, Mann M, Meng CK, et al. Electrospray ionization for mass spectrometry of large biomolecules. Science 1989;246(4926):64-71.

197. Yates JR, 3rd. Mass spectrometry and the age of the proteome. J Mass Spectrom 1998;33(1):1-19.

198. Taylor SC \& Posch A. The design of a quantitative western blot experiment. Biomed Res Int 2014;2014:361590.

199. Wheelock AM \& Wheelock CE. Trials and tribulations of 'omics data analysis: assessing quality of SIMCA-based multivariate models using examples from pulmonary medicine. Mol Biosyst 2013;9(11):2589-2596.

200. Sun W, Zheng Y, Lu Z, et al. Overexpression of S100A7 protects LPS-induced mitochondrial dysfunction and stimulates IL-6 and IL-8 in HaCaT cells. PLoS One 2014;9(3):e92927.

201. Tieu DD, Kern RC, \& Schleimer RP. Alterations in epithelial barrier function and host defense responses in chronic rhinosinusitis. J Allergy Clin Immunol 2009;124(1):3742.

202. Kulski JK, Lim CP, Dunn DS, et al. Genomic and phylogenetic analysis of the S100A7 (Psoriasin) gene duplications within the region of the S100 gene cluster on human chromosome 1q21. J Mol Evol 2003;56(4):397-406.

203. Lindbom J, Ljungman AG, Lindahl M, et al. Expression of members of the phospholipase A2 family of enzymes in human nasal mucosa. Eur Respir $J$ 2001;18(1):130-138.

204. Valentin E \& Lambeau G. Increasing molecular diversity of secreted phospholipases $\mathrm{A}(2)$ and their receptors and binding proteins. Biochim Biophys Acta 2000;1488(12):59-70.

205. Mitsuishi M, Masuda S, Kudo I, et al. Human group III phospholipase A2 suppresses adenovirus infection into host cells. Evidence that group III, V and X phospholipase A2s act on distinct cellular phospholipid molecular species. Biochim Biophys Acta 2007;1771(11):1389-1396.

206. Nitsch-Osuch A \& Brydak LB. Influenza viruses resistant to neuraminidase inhibitors. Acta Biochim Pol 2014;61(3):505-508.

207. Lindahl M, Irander K, Tagesson C, et al. Nasal lavage fluid and proteomics as means to identify the effects of the irritating epoxy chemical dimethylbenzylamine. Biomarkers 2004;9(1):56-70.

208. Emboriadou M, Hatzistilianou M, Magnisali C, et al. Human neutrophil elastase in RSV bronchiolitis. Ann Clin Lab Sci 2007;37(1):79-84. 
209. Kohlgraf KG, Ackermann AR, Burnell KK, et al. Quantitation of SPLUNC1 in saliva with an xMAP particle-based antibody capture and detection immunoassay. Arch Oral Biol 2012;57(2):197-204.

210. Fantuzzi G, Righi E, Predieri G, et al. Airborne trichloramine ( $\mathrm{NCl}(3))$ levels and selfreported health symptoms in indoor swimming pool workers: dose-response relationships. J Expo Sci Environ Epidemiol 2013;23(1):88-93.

211. Zwiener C, Richardson SD, DeMarini DM, et al. Drowning in disinfection byproducts? Assessing swimming pool water. Environ Sci Technol 2007;41(2):363372.

212. Garcia-Montoya IA, Cendon TS, Arevalo-Gallegos S, et al. Lactoferrin a multiple bioactive protein: An overview. Biochim Biophys Acta 2011.

213. Valenti P \& Antonini G. Lactoferrin: an important host defence against microbial and viral attack. Cell Mol Life Sci 2005;62(22):2576-2587.

214. van de Graaf EA, Out TA, Kobesen A, et al. Lactoferrin and secretory IgA in the bronchoalveolar lavage fluid from patients with a stable asthma. Lung 1991;169(5):275-283.

215. McCarthy C, Saldova R, Wormald MR, et al. The role and importance of glycosylation of acute phase proteins with focus on alpha-1 antitrypsin in acute and chronic inflammatory conditions. J Proteome Res 2014;13(7):3131-3143.

216. Lee YS, Chen PW, Tsai PJ, et al. Proteomics analysis revealed changes in rat bronchoalveolar lavage fluid proteins associated with oil mist exposure. Proteomics 2006;6(7):2236-2250.

217. Ryckman C, Vandal K, Rouleau P, et al. Proinflammatory activities of S100: proteins S100A8, S100A9, and S100A8/A9 induce neutrophil chemotaxis and adhesion. $J$ Immunol 2003;170(6):3233-3242.

218. Turk V, Stoka V, \& Turk D. Cystatins: biochemical and structural properties, and medical relevance. Front Biosci 2008;13:5406-5420.

219. Johansen FE, Braathen R, \& Brandtzaeg P. Role of $\mathrm{J}$ chain in secretory immunoglobulin formation. Scand J Immunol 2000;52(3):240-248.

220. Norderhaug IN, Johansen FE, Schjerven H, et al. Regulation of the formation and external transport of secretory immunoglobulins. Crit Rev Immunol 1999;19(5-6):481508.

221. Morjaria JB, Caruso M, Rosalia E, et al. Preventing progression of allergic rhinitis to asthma. Curr Allergy Asthma Rep 2014;14(2):412.

222. Graff P, Fredriksson M, Jönsson P, et al. Non-sensitising air pollution at workplaces and adult-onset asthma in the beginning of this millennium. Int Arch Occup Environ Health 2011;84:797-804.

223. Halayko AJ \& Ghavami S. S100A8/A9: a mediator of severe asthma pathogenesis and morbidity? Can J Physiol Pharmacol 2009;87(10):743-755.

224. Irander K, Borres MP, \& Ghafouri B. The effects of physical exercise and smoking habits on the expression of SPLUNC1 in nasal lavage fluids from allergic rhinitis subjects. Int J Pediatr Otorhinolaryngol 2014;78(4):618-622.

225. Toren K, Qvarfordt I, Bergdahl IA, et al. Increased mortality from infectious pneumonia after occupational exposure to inorganic dust, metal fumes and chemicals. Thorax 2011;66(11):992-996. 


\section{Papers}

The articles associated with this thesis have been removed for copyright reasons. For more details about these see:

http://urn.kb.se/resolve?urn=urn:nbn:se:liu:diva-117343 